\title{
Mechanical and thermal properties of graphene sulfonate nanosheet reinforced sacrificial
}

\section{concrete at elevated temperatures}

Hong-yan Chu ${ }^{\text {a, b }}$, Jin-yang Jiang ${ }^{\text {a, }}{ }^{* *}$, Wei Sun ${ }^{\text {a, b }}$, Mingzhong Zhang ${ }^{\text {c }}$

${ }^{a}$ School of Materials Science and Engineering, Southeast University, Nanjing 211189, China

b Jiangsu Key Laboratory of Construction Materials, Nanjing 211189, China

${ }^{\mathrm{c}}$ Advanced and Innovative Materials (AIM) Group, Department of Civil, Environmental and Geomatic Engineering, University College London, London WC1E 6BT, UK

Abstract: Progress in the field of nanomaterials presents an opportunity to improve the performance of cementitious composites via graphene or its derivatives. This paper presents an experimental study on mechanical and thermal properties of sacrificial concrete without and with graphene sulfonate nanosheets (GSNSs) during high temperature exposure. The microstructure, porosity, mechanical strengths, thermal analysis, coefficient of thermal expansion, thermal diffusivity and ablation behaviour of sacrificial concrete during exposure to various temperatures up to $1000{ }^{\circ} \mathrm{C}$ were comprehensively investigated. Two new experimental apparatuses were developed and used to measure mechanical strengths of sacrificial concrete at elevated temperatures. It was found that the compressive strength, splitting tensile strength, thermal diffusivity and decomposition enthalpy of sacrificial concrete were increased by $12.98-25.36 \%, 8.66-34.38 \%, 25.00-103.23 \%$ and $4.23 \%$ respectively when adding $0.1 \mathrm{wt} \%$ GSNSs, while the porosity and ablation velocity of sacrificial concrete were reduced by $3.01-6.99 \%$ and $4.14 \%$ respectively due to the incorporation of GSNSs.

Keywords: sacrificial concrete; graphene nanosheet; mechanical strength; thermal analysis; microstructure

\section{Introduction}

\footnotetext{
* Corresponding author. Tel.: +86-025-52090667; E-mail address: jiangjinyang16@163.com (J.-y. Jiang)

+ Corresponding author. Tel.: +44 0207679 7299; E-mail address: mingzhong.zhang@ucl.ac.uk (M. Zhang) 
Cementitious composites are the most important and widely used civil engineering materials. Recent progress in the field of nanotechnology has provided an opportunity to improve the performance of cementitious composites by incorporating nano-sized materials, such as nano-SiO 2 [1-3], nano- $\mathrm{TiO}_{2}[4]$, nano- $\mathrm{Al}_{2} \mathrm{O}_{3}[5,6]$, nano- $\mathrm{Fe}_{3} \mathrm{O}_{4}$ [7] and carbon nanotubes [8-10]. When small particles were evenly distributed in cementitious materials, they served as nucleation sites, as a result of which the degree of cement hydration can be improved [11]. In addition, the nanomaterials contribute to the microstructural regulation of cement composites and the microstructure of cementitious materials can be improved significantly by adding nanomaterials [12], and nanomaterial has nano-filler effect on cementitious materials [13].

Nowadays, graphene as a new kind of nanomaterial has attracted a lot of interest. Graphene manifests a single atom thickness of $2 \mathrm{D}$ carbon atoms planar sheet with $\mathrm{sp}^{2}$ bonded pattern and has distinguished optical, electrical, thermal and mechanical properties [14]. The electrical conductivity, thermal conductivity, tensile strength and elastic modulus of graphene are $2000 \mathrm{~S} / \mathrm{cm}, 5300 \mathrm{~W} / \mathrm{mK}$, $130 \mathrm{GPa}$ and $1 \mathrm{TPa}$ [15-17], respectively. The specific surface area of one single graphene sheet is $2630 \mathrm{~m}^{2} / \mathrm{g}$ [16]. Because of its excellent properties, graphene has a promising prospect when combined with cementitious composites. However, the use of graphene is still hampered by its poor water dispersing ability and high production cost. As derivatives of graphene, graphene nanosheets (GNSs) and graphene oxide nanosheets (GONSs) are also carbon nanomaterials composed of graphene stacks or graphene sheets [18-21]. GONSs are oxides of GNSs and contain oxygen functional groups that attach on the basal plans and edges of graphene oxide sheets. The functional groups can modify the van der Waals interactions between the GONSs and thus lead to the improvement of the water dispersing capability of GONSs [22]. Moreover, the GNSs and GONSs are lower-cost nanomaterials as compared to graphene. 
So far, an increasing number of studies have been conducted to investigate the influence of graphene or its derivatives on properties of cementitious composites. Horszczruk et al. [23] reported that the Young's modulus of cement paste was significantly enhanced by adding $3 \mathrm{wt} \%$ graphene oxide. Bulut [24] explored the effect of graphene nanopellets on mechanical properties of basalt/epoxy composites and found that the mechanical properties of basalt/epoxy composites could be significantly improved due to the addition of $0.1 \mathrm{wt} \%$ graphene nanopellets. Murugan et al. [25] observed that the addition of $0.02 \mathrm{wt} \%$ GONS by weight of cement can lead to an increase of up to $70 \%$ and $23 \%$ respectively in the 7 -day and 28-day flexural strength of cement paste. Lu et al. [26] concluded that the compressive strength and flexural strength of cement paste were increased by $11.05 \%$ and $16.20 \%$, respectively, when adding $0.05 \mathrm{wt} \%$ graphene oxide. Apart from enhancing mechanical properties, the self-sensing ability of cementitious materials can also be improved due to the addition of conductive nanomaterials. Le et al. [20] found that the GNSs could be used to characterise the damage in cement composites due to their extraordinary electrical conductivity. The self-sensing ability of GNSs reinforced cement composites was found to be similar to the selfinduction of carbon fibre reinforced conductive concrete [27]. Although a great deal of research has been conducted on cement paste or mortar reinforced with graphene or its derivatives, there are only few investigations of the use of them in concrete. In addition, there is no publication devoted to properties of graphene sulfonate nanosheets (GSNSs) reinforced concrete. Compared to GONSs, the production cost of GSNSs is lower. The sulfonic groups contained in GSNSs are similar to that of hydroxyl functional $(-\mathrm{OH})$ groups in GONSs, thus the GSNSs may also be used to improve the properties of cementitious materials.

As a key component of European Pressurized Water Reactor, sacrificial concrete is designed to reduce the leakage potential of radioactive materials in severe nuclear accidents through its encasing 
function [28]. Ferro-siliceous sacrificial concrete and siliceous sacrificial concrete are the two most widely used sacrificial concrete. On one hand, sacrificial concrete can melt and mix with corium (a molten mixture of fuel material, partially or totally oxidized cladding, non-volatile fission products and various structural materials) reducing the temperature of corium. On the other hand, the $\mathrm{SiO}_{2}$ from sacrificial concrete can oxidize $\mathrm{Zr}$ in the corium and the glassily matrix formed by molten $\mathrm{SiO}_{2}$ can enwrap the radioactive fission products [29]. In case of fire or nuclear accident, concrete is exposed to elevated temperatures. Although extensive research on the behaviour of concrete subjected to high temperatures has been reported so far [30-34], investigation on the thermal properties of sacrificial concrete is rare, especially on its mechanical properties during elevated temperature exposure. Chu et al. [35] have recently carried out a systematic study on mechanical and physicochemical properties of ferro-siliceous sacrificial concrete after high temperature exposure, and observed that the compressive strength-ultrasonic pulse velocity (UPV) and splitting tensile strength-UPV relationships followed a Weibull distribution and was in exponential form, respectively. It is worth pointing out that the mechanical properties of concrete during high temperature exposure and after exposure (i.e., concrete has been cooled down) are different, as the damage due to elevated temperatures can be retrieved during cooling. Overall, only very little information is available on the properties of sacrificial concrete at high temperatures. Moreover, the effects of GSNSs on thermal and mechanical properties of sacrificial concrete have rarely been studied elsewhere.

The main purpose of this paper is to investigate the mechanical and thermal properties of sacrificial concrete without and with GSNSs before and during high temperature exposure, which extends authors' recently published work [36] from siliceous sacrificial concrete to ferro-siliceous sacrificial concrete. Two new experimental facilities for measuring the compressive strength and splitting tensile strength of sacrificial concrete during elevated temperature exposure are developed. Afterwards, a 
series of experiments were carried out to estimate the microstructure, porosity, compressive strength, splitting tensile strength, thermal analysis, coefficient of thermal expansion (CTE), thermal diffusivity and ablation behaviour of sacrificial concrete without and with GSNSs before and at different temperatures, i.e., $200,400,600,800$, and $1000^{\circ} \mathrm{C}$.

\section{Experimental programme}

\subsection{Materials}

Silica fume and Class I fly ash (equivalent to ASTM C 618 Class F fly ash) were used as supplementary cementitious materials in the study. The chemical composition of cement and supplementary cementitious materials are shown in Table 1. The specific gravity of cement and silica fume was 3.15 and 2.22 , respectively. The specific surface of cement and silica fume was 362.20 $\mathrm{m}^{2} / \mathrm{kg}$ and $2.79 \times 10^{4} \mathrm{~m}^{2} / \mathrm{kg}$, respectively. The compressive strength of cement mortar (water/cement/ sand $=1: 2: 6$ ) at 28 days was $62.8 \mathrm{MPa}$.

Silica sand and iron ore supplied by Nuclear Industry Nonmetallic Mineral Powders Co., Ltd (Liuzhou, China) and Nuclear Science and Technology Co., Ltd (Tongchang, China) respectively were used as aggregates. The silica sand was composed of $\mathrm{SiO}_{2}, \mathrm{CaCO}_{3}$, and $\mathrm{MgCO}_{3}$, the weight percentages of which were $99.88 \%, 0.058 \%$, and $0.062 \%$, respectively. The iron ore contained 92.22 $\mathrm{wt} \% \mathrm{Fe}_{2} \mathrm{O}_{3}, 7.61 \mathrm{wt} \% \mathrm{SiO}_{2}$, and $0.17 \mathrm{wt} \% \mathrm{CaCO}_{3}$. Table 2 shows the sieve analysis of aggregates.

A superplasticizer of polycarboxylate supplied by Sobute New Materials Co., Ltd (Nanjing, China) was used to gain a satisfactory fluidity of sacrificial concrete. The solid content and water-reducing rate of superplasticizer were $40.0 \mathrm{wt} \%$ and $33.9 \%$, respectively. The physical and mechanical properties of polypropylene fibre used in this work are presented in Table 3 . The graphene sulfonate solution was obtained from Graphene-Tech Co., Ltd (Suzhou, China). The solid content, particle size, and thickness of GSNSs were $10.5 \mathrm{wt} \%, 50-100 \mu \mathrm{m}$, and 1-2 nm, respectively. 


\subsection{Specimen preparation}

Table 4 shows the mixtures of sacrificial concrete that were carefully designed in accordance with our previous research findings shown in literature [28] and further improved via the addition of GSNSs. Herein, the ferro-siliceous sacrificial concrete mixtures without and with GSNSs were marked as FC and FCG, respectively. The content of GSNSs in the FCG mixture was 0.1 wt $\%$ of binders (cement and supplementary cementitious materials).

Based on the above mixtures, the cubic specimens $(150 \times 150 \times 150 \mathrm{~mm})$ of sacrificial concrete were cast. After casting, the molds were covered with plastic sheets and were cured for $24 \mathrm{~h}$ at ambient conditions. Afterwards, the molds were removed and the specimens were cured in a standard curing room $\left(21 \pm 1{ }^{\circ} \mathrm{C}\right.$ and relative humidity of above $\left.95 \%\right)$ for 28 days. In total, 60 cubic specimens were prepared for each mixture. It should be highlighted that, in order to obtain a homogeneous mixture, the polypropylene fibre was dispersed carefully by hand, and then mixed with cement, silica sand and iron ore using a mixer for 5 min. Meanwhile, the GSNSs solution was mixed with superplasticizer, and a part of water was subsequently poured into the mixture and stirred evenly. Afterwards, the mixed solution was added to the dry materials and mixed in the mixer for another $5 \mathrm{~min}$. Note that the rest of water was firstly used to flush the mixed solution container, before it was added to the mixer.

\subsection{Test methods}

\subsubsection{Microstructure}

To detect the microstructure of sacrificial concrete without and with GSNSs, a FEI 3D environmental scanning electronic microscopy (ESEM) was used. The micrographs of specimens were taken at ambient temperature and after exposure to high temperatures, i.e., 200, 400, 600, 800, and $1000^{\circ} \mathrm{C}$. 


\subsubsection{Porosity}

A Micromeritics AutoPore IV 9510 mercury intrusion porosimetry (MIP) was used to estimate the pore evolution of sacrificial concrete without and with GSNSs at elevated temperatures.

\subsubsection{Mechanical properties}

Fig. 1 shows the two new experimental facilities that were developed to measure the compressive strength and splitting tensile strength of sacrificial concrete without and with GSNSs during elevated temperature exposure.

The compressive strength measuring equipment consists of a universal testing machine and an electrical furnace. The outline of the universal testing machine with a maximum load capacity of 3000 $\mathrm{kN}$ is composed of steel columns and beams. The top and bottom blocks of the machine are made of a high temperature resistant material that still has high strength and stiffness at $1200{ }^{\circ} \mathrm{C}$. The red frame in Fig. 1a denotes the electrical furnace, the heating rate and maximum temperature of which are 0.5$15^{\circ} \mathrm{C} / \mathrm{min}$ and $1500{ }^{\circ} \mathrm{C}$, respectively. The furnace is bigger enough to hold three padding blocks on the slide rail and there is an electric actuator to push the padding blocks along the track, thus the compressive strength of three specimens can be measured at a time. The silicon carbide rods are distributed evenly on the side walls of furnace. A thermocouple is installed at the middle of furnace to monitor the temperature of furnace chamber. There are two displacement measuring bars made of a high temperature resistant material that has rather small coefficient of thermal expansion: one is on the top of padding block; the other is on the top of the steel plate with a thickness of $4 \mathrm{~mm}$ between the upper surface of specimen and the downward surface of top bearing block. Two grating displacement sensors with a precision of $\pm 1 \mu \mathrm{m}$ connect with two displacement measuring bars, respectively, such that the deformation of specimen during the compression test can be obtained accurately. In addition, there are cooling systems on the top and bottom blocks of universal testing 
machine and electric actuator. The cooling is achieved by letting the cool water flow through the cooling systems.

Similarly, the splitting tensile strength measuring apparatus is also composed of a universal testing machine and an electrical furnace, as shown in Fig. 1b. The universal testing machine, electrical furnace, displacement measuring bars and cooling systems in the splitting tensile strength measuring apparatus are the same as those used in compression test except those: the maximum load capacity of the universal testing machine is $300 \mathrm{kN}$ and the displacement measuring bars are on the left and right sides of furnace.

In this work, the specimens were heated from ambient temperature, i.e., $25^{\circ} \mathrm{C}$ to $200,400,600$, 800 , and $1000^{\circ} \mathrm{C}$ at a heating rate of $5^{\circ} \mathrm{C} / \mathrm{min}$. According to literature [34], the specimens were held at the target temperature for $2 \mathrm{~h}$ in order to ensure a uniform temperature throughout each specimen. After that, the compressive strength and splitting tensile strength of specimens before and during high temperature exposure were measured using the developed two new experimental facilities with a loading rate of $0.3 \mathrm{MPa} / \mathrm{s}$ and $0.03 \mathrm{MPa} / \mathrm{s}$, respectively.

\subsubsection{Thermal analysis}

Thermogravimetric analysis (TGA) and differential scanning calorimetry (DSC) of sacrificial concrete without and with GSNSs were performed via a simultaneous thermal analyzer (NETZSCH STA449 F3). The experimental conditions were: at standard atmospheric pressure, in nitrogen circumstance and at the heating rate of $10{ }^{\circ} \mathrm{C} / \mathrm{min}$ up to $1300^{\circ} \mathrm{C}$. The specimen used in the TGA experiment was ground into power by hand using an agate mortar.

\subsubsection{Coefficient of thermal expansion}

A dynamic thermal mechanical analyzer (NETZSCH TMA402 F1) was used to measure the thermal deformation of sacrificial concrete at elevated temperatures. The thermal deformation of 
sacrificial concrete without and with GSNSs was carried out in accordance with ASTM E 831-03 on $8 \times 8 \times 20 \mathrm{~mm}$ prismatic specimens that were sliced from the $150 \times 150 \times 150 \mathrm{~mm}$ specimens. The linear variation in length of each specimen was measured by the device at a heating rate of $10{ }^{\circ} \mathrm{C} / \mathrm{min}$. The relationship between thermal strain and CTE can be determined as follows

$$
\begin{aligned}
& \varepsilon=\Delta L / L_{0} \\
& \Delta L=\alpha \cdot L_{0} \cdot \Delta T
\end{aligned}
$$

where $\varepsilon$ is the thermal strain, $\Delta L$ is the unit length change, $L_{0}$ is the initial length of the specimen, $\alpha$ is the CTE and $\Delta T$ is the temperature difference.

Substituting Eq. (2) to Eq. (1), the relationship between thermal strain and CTE can be derived as

$$
\varepsilon=\alpha \cdot \Delta T
$$

As such, the CTE of sacrificial concrete between ambient temperature $\left(25^{\circ} \mathrm{C}\right)$ and each target temperature $\left(200,400,600,800\right.$ and $\left.1000^{\circ} \mathrm{C}\right)$ can be calculated using Eq. (3).

Assume that sacrificial concrete is a homogeneous material, the relationship between its volumetric CTE $\beta$ and linear CTE $\alpha$ can be expressed as

$$
\beta=3 \alpha
$$

\subsubsection{Thermal diffusivity}

The thermal diffusivity of a material is defined as the ratio of the heat transmitted to the heat stored by unit mass of the material, as seen in Eq. (5). In steady or quasi-steady states, the heat transmission through conduction is controlled by thermal diffusivity.

$$
\mathrm{a}=\lambda /(c \cdot \rho)
$$

where $\mathrm{a}$ is the thermal diffusivity, $\lambda$ is the thermal conductivity, $c$ is the specific heat and $\rho$ is the density of sacrificial concrete.

The thermal conductivity and specific heat of sacrificial concrete before and during high 
temperature exposure $\left(25,200,400,600,800\right.$, and $\left.1000{ }^{\circ} \mathrm{C}\right)$ were measured by a laser thermal constant analyzer (NETZSCH LFA457) in accordance with ASTM E 1461-13. The laser flash source was Neodymium-doped gadolinium gallium garnet crystal with a radiant pulse energy up to $18.5 \mathrm{~J}$. The temperature evolution of specimen was detected by an advanced non-contact infrared detector. The specimen size used in the experiment was $10 \times 10 \times 1 \mathrm{~mm}$. The initial density $\left(\rho_{0}\right)$ of sacrificial concrete was determined according to the Chinese standard GB/T 50080-2002 and can be expressed as

$$
\rho_{0}=\frac{m_{0}}{V_{0}}
$$

where $m_{0}$ and $V_{0}$ represent the initial mass and initial volume, respectively.

The density of sacrificial concrete during high temperatures $\rho^{T}$ can be calculated using the following equation

$$
\rho^{T}=\frac{m^{T}}{V^{T}}=\frac{(1-\gamma) m_{0}}{(1+\beta) V_{0}}=\frac{(1-\gamma)}{(1+\beta)} \rho_{0}
$$

where $\gamma$ is the mass loss ratio of sacrificial concrete.

Based on the results of TGA experiment, the mass loss ratio of sacrificial concrete during high temperature exposure can be determined. Accordingly, the density of sacrificial concrete at high temperatures can be calculated with Eq. (7). Afterwards, the thermal diffusivity of sacrificial concrete before and during elevated temperature exposure can be obtained.

\subsubsection{Ablation behaviour}

Based on the theory of heat transfer, the ablation velocity $(v)$ of sacrificial concrete is associated with the heat flux $(\dot{Q})$ through sacrificial concrete and their relationship can be expressed by

$$
\mathrm{v}=\frac{\dot{Q}}{\rho \cdot A \cdot \Delta H}
$$

where $\rho, A$, and $\Delta H$ denote the density, ablating area and decomposition enthalpy of sacrificial concrete, respectively. 
The enthalpy of sacrificial concrete can be estimated by integration of its DSC curve [37]. The zero point of enthalpy is set to $25{ }^{\circ} \mathrm{C}$ here. The decomposition temperature of sacrificial concrete can be determined via a computer-controlled radiant electrically furnace with a heating rate of $5{ }^{\circ} \mathrm{C} / \mathrm{min}$. Subsequently the decomposition enthalpy can be obtained, as such the ablation velocity of sacrificial concrete can be quantified.

It should be mentioned that in order to improve the accuracy of experimental results three repeated measurements were undertaken on the porosity, compressive strength, splitting tensile strength, TGA, DSC, CTE and thermal diffusivity tests at each target temperature. Only the mean values were presented in the work.

\section{Results and discussion}

\subsection{Microstructure}

Fig. 2 shows the ESEM images of sacrificial concrete before and after exposure to 25, 200, 400, 600,800 and $1000^{\circ} \mathrm{C}$. Initially, the matrix of sacrificial concrete without GSNSs (i.e., FC) presented a continuous microstructure without obvious micro-cracks. At 200 and $400{ }^{\circ} \mathrm{C}$, a small number of micro-cracks could be observed. More micro-cracks emerged when the temperature reached $600{ }^{\circ} \mathrm{C}$. At $800{ }^{\circ} \mathrm{C}$, the micro-cracks connected to each other across the specimen. After exposure to $1000^{\circ} \mathrm{C}$, the matrix of sacrificial concrete became amorphous and some micro-cracks appeared in the aggregates. The microstructural evolution of sacrificial concrete with GSNSs (i.e., FCG) with increasing temperature was similar to that of FC, as shown in Fig. 2b. However, FCG was more compact than FC at ambient temperature. Two long channels let by molten polypropylene fibres can be observed in FCG at 200 and $400{ }^{\circ} \mathrm{C}$, and a polypropylene fibre can be found at $200{ }^{\circ} \mathrm{C}$. This result indicates that some polypropylene fibres in FCG were melted when FCG was exposed to $200{ }^{\circ} \mathrm{C}$, while the other polypropylene fibres still possessed their initial morphology, although the melting 
temperature of the polypropylene fibres used in this work was $169^{\circ} \mathrm{C}$ (see Table 4) and they should be melted after exposure to $200{ }^{\circ} \mathrm{C}$.

Both the cement paste and aggregate of sacrificial concrete were significantly influenced by elevated temperature due to the pressure induced by moistures and carbon dioxide release [28], and the thermal stress resulting from thermal gradient [38] or thermal incompatibility [39]. Accordingly, the microstructures of sacrificial concrete were gradually damaged as temperature increased, which led to degradation of sacrificial concrete.

It can be seen from Fig. 3a that GSNSs had reinforcing and toughing effects on the microstructure of sacrificial concrete. The yellow square in Fig. 3a was enlarged and presented in Fig. $3 \mathrm{~b}$ to show details. The cumulate plate-shaped products were clearly observed in Fig. 3b, which indicated that the addition of GSNSs resulted in a denser microstructure of sacrificial concrete. The energy dispersive spectrometer (EDS) analysis was performed on the blue square in Fig. $3 \mathrm{~b}$ to evaluate the elemental compositions of this area. The main elemental compositions were found to be $\mathrm{C}, \mathrm{O}, \mathrm{Ca}, \mathrm{S}$ and $\mathrm{Fe}$, the weight percentages of which were $46.42 \%, 34.06 \%, 10.85 \%, 4.41 \%$ and $3.94 \%$, respectively. This result implied that the formation of the cumulative plate-shaped products was because of the addition of GSNSs, because the sulfonic groups in GSNSs might react with hydration products to form covalent bonds, which was similar to poly methyl methacrylate in graphene sheets [40]. Therefore, the GSNSs added to sacrificial concrete could have reinforcing and toughing effects on the microstructure of sacrificial concrete.

\subsection{Porosity}

Fig. 4 shows the porosity and pore size distribution of sacrificial concrete at ambient temperature and after exposure to $200,400,600,800$, and $1000^{\circ} \mathrm{C}$. With the increase of temperature, the porosity of sacrificial concrete continually increased, which is consistent with the findings for high-strength 
concrete subjected to elevated temperatures $[41,42]$. The increase of porosity of sacrificial concrete can be attributed to the loss of water in capillary pores and hydration products [43], cracks induced by the incompatible deformation between cement paste and aggregate [39], and the channels due to the melting of polypropylene fibres in sacrificial concrete (see Fig. 2b).

As shown in Fig.4a, the porosity of sacrificial concrete was increased by $26.18 \%$ (FC) and $28.97 \%$ (FCG), respectively, for temperatures ranging from 25 to $400{ }^{\circ} \mathrm{C}$. This was followed by a rapid increase in porosity during $400-800{ }^{\circ} \mathrm{C}$ : $128.44 \%$ for $\mathrm{FC}$ and $130.85 \%$ for $\mathrm{FCG}$, which is in consistence with the increasing number of cracks in the microstructure of sacrificial concrete formed in the same temperature range, as seen in Fig.2. Afterwards, there was a gradual increase in porosity of sacrificial concrete when the temperature increased from 800 to $1000{ }^{\circ} \mathrm{C}$. Compared to that at ambient temperature, the porosity of sacrificial concrete after exposure to $1000^{\circ} \mathrm{C}$ was increased by $197.29 \%$ (FC) and 203.97\% (FCG), respectively.

Over the whole range of temperatures, the porosity of FCG was always lower than that of FG. The porosity of FCG was 3.01-6.99\% less than that of FG due to the addition of GSNSs, which can be explained by the following two aspects. On one hand, the GSNSs had reinforcing and toughing effects on the microstructure of sacrificial concrete (see Fig. 3b) leading to a reduction in porosity of sacrificial concrete. On the other hand, the thermal gradient in FCG was lower than that of FC due to the addition of GSNSs [38], as a result of which the induced thermal damage in FCG was lower than that in FC.

With regards to pore size distribution, multiple peaks can be observed for temperatures between 25 ${ }^{\circ} \mathrm{C}$ and $1000^{\circ} \mathrm{C}$ and the threshold pore size increased with increasing temperature, as shown in Figs. $4 \mathrm{~b}$ and $4 \mathrm{c}$. At 25,400 and $800^{\circ} \mathrm{C}$, most of the pore size of FC were within two peak intervals $(0.01,0.07)$ $\mu \mathrm{m},(0.08,2.18) \mu \mathrm{m}$, and $(0.17,24.18) \mu \mathrm{m}$. There was a similar trend for FCG, but its pore size was 
within a smaller range, from $0.01-0.06 \mu \mathrm{m}$ at $25^{\circ} \mathrm{C}$, to $0.08-2.13 \mu \mathrm{m}$ at $400{ }^{\circ} \mathrm{C}$, to $0.20-23.08 \mu \mathrm{m}$ at $800{ }^{\circ} \mathrm{C}$. These results could explain why the porosity of sacrificial concrete increased slowly in the range of $25-400{ }^{\circ} \mathrm{C}$, while increased rapidly during $400-800{ }^{\circ} \mathrm{C}$.

\subsection{Residual compressive strength}

Fig. 5 shows the residual compressive strength and relative residual compressive strength of sacrificial concrete at elevated temperatures that is defined as the ratio of residual compressive strength at elevated temperature to compressive strength at ambient temperature. As seen in Fig.5a, the compressive strength of sacrificial concrete decreased monotonically with the increase of temperature, which is consistent with the change of compressive strength of self-consolidating concrete $[31,44,45]$ and siliceous sacrificial concrete [36] exposed to elevated temperatures. The compressive strength loss can be attributed to the increase in porosity of sacrificial concrete over the same range of temperature (see Fig.4a) and to the decrease in both stiffness and cohesive strength of C-S-H gel [46]. In addition, the compressive strength of FCG was always higher than that of FC over the whole range of $25-1000{ }^{\circ} \mathrm{C}$ and the compressive strength of sacrificial concrete was increased by $12.98-25.36 \%$ due to the incorporation of GSNSs, which have reinforcing effects. The compressive strength of FCG at 25,600 and $1000{ }^{\circ} \mathrm{C}$ was, $12.98 \%, 20.06 \%$ and $25.36 \%$ higher than that of FC, respectively. The decreasing amplitude of compressive strength for FCG was smaller than that of FC during exposure to elevated temperatures, which can be ascribed to the lower thermal damage in FCG than that in FC at high temperatures due to the addition of GSNSs.

As seen in Fig.5b, the change in relative residual compressive strength of sacrificial concrete against temperature followed a similar trend of that in compressive strength. The relative residual compressive strength of FCG was always higher than that of FC at each target temperature, which indicated that the induced thermal damage FCG was lower than that of FC at high temperatures. At 
$200{ }^{\circ} \mathrm{C}$, the relative residual compressive strength of FC and FCG was $84.93 \%$ and $87.15 \%$, respectively, which was followed by a sharp drop in the range of $400-600{ }^{\circ} \mathrm{C}$. The relative residual compressive strength of FC and FCG was only $34.22 \%$ and $36.37 \%$ at $600{ }^{\circ} \mathrm{C}$. The relative residual compressive strength kept decreasing with temperature during $800-1000{ }^{\circ} \mathrm{C}$ and was merely $15.71 \%$ (FC) and $17.43 \%(\mathrm{FCG})$ at $1000{ }^{\circ} \mathrm{C}$. Overall, the critical temperature of sacrificial concrete was found to be $400-600{ }^{\circ} \mathrm{C}$, where the most dramatic decrease in relative residual compressive strength occurred.

\subsection{Residual splitting tensile strength}

Fig. 6 shows the residual splitting tensile strength and the relative residual splitting tensile strength of sacrificial concrete without and with GSNSs at various temperatures. The relative residual splitting tensile strength is defined as the ratio of residual splitting tensile strength at high temperature to splitting strength at ambient temperature. As seen in Fig.6a, the residual splitting tensile strength of sacrificial concrete declined continually as temperature increased, which is in good agreement with previous studies on siliceous sacrificial concrete $[28,36]$ and high-strength concrete [47] exposed to elevated temperatures. The decrease in splitting tensile strength of sacrificial concrete was associated with their increasing porosity. The splitting tensile strength of FCG was invariably higher than that of FC due to the addition of GSNSs that resulted in an increase of 8.66-34.38\% in the splitting tensile strength of sacrificial concrete. In detail, the splitting tensile strength of FCG at 25, 600 and $1000{ }^{\circ} \mathrm{C}$ was $8.66 \%, 21.15 \%$ and $34.38 \%$ higher than that of FC, respectively.

The relative residual splitting tensile strength of sacrificial concrete decreased monotonically with increasing temperature, as shown in Fig.5b. Similarly, the relative residual splitting tensile strength of FCG was always higher than that of FC at elevated temperatures. There was no obvious drop in the relative residual splitting tensile strength of sacrificial concrete at $200{ }^{\circ} \mathrm{C}$, that was $86.60 \%$ and $87.65 \%$ for FC and FCG, respectively. The relative residual splitting tensile strength declined sharply 
in the range of $400-600{ }^{\circ} \mathrm{C}$ that is accordance with that for relative residual compressive strength as discussed above. The relative residual splitting tensile strength at $600{ }^{\circ} \mathrm{C}$ was $29.89 \%(\mathrm{FC})$ and $33.12 \%$ (FCG), respectively. This was followed by a relatively slower decrease in the relative residual splitting tensile strength during $800-1000{ }^{\circ} \mathrm{C}$, which was only $9.23 \%$ (FC) and $11.34 \%$ (FCG) respectively at $1000{ }^{\circ} \mathrm{C}$.

In order to make a direct comparison analysis the relative residual compressive strength and splitting tensile strength of sacrificial concrete at various temperatures were plotted together in Fig. 7. The relative residual compressive strength of sacrificial concrete was found to be higher than the relative residual splitting tensile strength at high temperatures, except for FCG at $200{ }^{\circ} \mathrm{C}$. For instance, the former was $15.18 \%$ (FC) and $18.06 \%$ (FCG) respectively higher than the latter at $400{ }^{\circ} \mathrm{C}$. These results implied that the elevated temperature has a more severe effect on the splitting tensile strength of sacrificial concretes than compressive strength.

\subsection{Thermal analysis}

Fig. 8 shows the effects of temperature on thermal decomposition (TGA) and heat absorption/desorption (DSC) of sacrificial concrete. As seen in Fig.8a, the weight evolution of FC and FCG was exactly similar, which can be attributed to the nearly same mixtures of them (see Table 4). A quick weight loss can be observed in the TGA for sacrificial concrete in the range of $25-150^{\circ} \mathrm{C}$, which is consistent with that for self-compacting cement paste subjected to elevated temperatures [48]. The weight loss of sacrificial concrete in this range of temperature can be ascribed to the loss of evaporable water and part of physically bound water. Between $105^{\circ} \mathrm{C}$ and $700{ }^{\circ} \mathrm{C}$, the mass loss of sacrificial concrete indicated from TGA was associated with the loss of chemically bound water and dehydration of products [49]. At $700^{\circ} \mathrm{C}$, a significant loss in the weight of sacrificial concrete can be observed, which can be explained by the decarbonation of calcium carbonate. After that temperature, 
the curves of TGA changed smoothly, followed by another sharp drop in the weight of sacrificial concrete at about $1200{ }^{\circ} \mathrm{C}$ due to the melting of cement. In addition, the weight loss of FCG was slightly lower than that of FC in the range of $25-1300{ }^{\circ} \mathrm{C}$. The total weight loss of FC and FCG up to $1300{ }^{\circ} \mathrm{C}$ was $7.64 \%$ and $6.62 \%$, respectively.

As shown in Fig.8b, the DSC patterns of FC and FCG were also close to each other that is similar to the TGA curves, since the hydration products of them were essentially the same. The dehydration of sacrificial concrete occurred at about $100^{\circ} \mathrm{C}$ characterised by the loss of evaporable water and part of physically bound water and the decomposition of calcium hydroxide took place in the range of $400-600{ }^{\circ} \mathrm{C}$, which are in good agreement with the results presented in [49]. At approximately $580{ }^{\circ} \mathrm{C}$, the crystalline of quartz transformed from $\alpha$ to $\beta$ quartz and the decarbonation of calcium carbonate occurred at about $700{ }^{\circ} \mathrm{C}$, which is consistent with the conclusion drawn by Bazant and Kaplan [49] that the decomposition of calcium carbonate happens in the range of $600-900{ }^{\circ} \mathrm{C}$. The melting of cement was observed at approximately $1200{ }^{\circ} \mathrm{C}$ that is in accordance with experimental results presented in [37]. It is worth pointing out that the dehydration of hydrates is generally an ongoing process between $100^{\circ} \mathrm{C}$ and $850^{\circ} \mathrm{C}$.

\subsection{Coefficient of thermal expansion}

Fig.9 shows the thermal strain of sacrificial concrete without and with GSNSs. The thermal strain of sacrificial concrete increased continually with the increase of temperature. There was a sharp increase in the thermal strain in the range of $25-600{ }^{\circ} \mathrm{C}$ followed by a gradual increase after $600{ }^{\circ} \mathrm{C}$. The thermal strain of sacrificial concrete at elevated temperatures can result from different aspects. Accordingly, the mechanical properties of sacrificial concrete may degrade under these circumstances [41]. The loss of water in hydration products may lead to shrinkage of concrete [50]. The siliceous aggregates containing quartz can cause inner expansive force in concrete at about $580{ }^{\circ} \mathrm{C}$ due to the 
transformation of quartz from $\alpha$ to $\beta$ (see Fig. $8 \mathrm{~b}$ ) and thus lead to volumetric expansion of sacrificial concrete. This transformation was also observed in this work that resulted in a sudden increase in the thermal strain after $580^{\circ} \mathrm{C}$ for both $\mathrm{FC}$ and $\mathrm{FCG}$, as shown in Fig.9. The thermal strain of FC and FCG was almost the same in the range of $25-700{ }^{\circ} \mathrm{C}$ because of their similar mixtures (see Table 4). However, the thermal strain of FC tended to be higher than that of FCG after $700{ }^{\circ} \mathrm{C}$. This may be attributed to the relatively lower thermal gradient and thermal damage in FCG than those in FC above $700{ }^{\circ} \mathrm{C}$ due to the addition of GSNSs. The thermal strain of FC and FCG at $600{ }^{\circ} \mathrm{C}$ was found to be $13.32 \times 10^{-3}$ and $13.55 \times 10^{-3}$, respectively.

Fig.10 shows the first derivation of the thermal strain curves represents the phase changes on the specimens during high temperatures [51]. The first trough appeared at about $170{ }^{\circ} \mathrm{C}$, which may correspond to the melting of polypropylene fibres in sacrificial concrete. Two significant peaks in the curves emerged at approximately $580^{\circ} \mathrm{C}$, which can be associated with the transformation of quartz from $\alpha$ to $\beta$, as discussed in the experimental results of DSC (see Fig.8b). The other weak trough occurred at around $900{ }^{\circ} \mathrm{C}$, where the free calcium hydroxide turned into calcium oxide.

The CTE of sacrificial concrete without and with GSNSs, i.e., FC and FCG, can be calculated using Eq. (3) and is shown in Fig. 11. The CTE evolution of FC and FCG was very close, which agrees very well with the results of thermal strain as shown in Fig.9. A rapid increase in the CTE of sacrificial concrete was observed in the range of $25-150^{\circ} \mathrm{C}$ followed by a slight drop between $150{ }^{\circ} \mathrm{C}$ and 200 ${ }^{\circ} \mathrm{C}$ due to the evaporation of internal free water in calcium silicate hydrate $(\mathrm{C}-\mathrm{S}-\mathrm{H})$ gel $[51]$. After that, the CTE increased continually and then decreased until $1000^{\circ} \mathrm{C}$. The CTE of sacrificial concrete reached its maximum at about $600^{\circ} \mathrm{C}$. The increase of CTE with increasing temperature from $250{ }^{\circ} \mathrm{C}$ to $500{ }^{\circ} \mathrm{C}$ can be attributed to the decomposition of C-S-H gel. As temperature increased, the water evaporated from sacrificial concrete leading to the shrinkage of matrix, and the CTE of sacrificial 
concrete decreased accordingly. However, the CTE of sacrificial concrete increased significantly between $550{ }^{\circ} \mathrm{C}$ and $600{ }^{\circ} \mathrm{C}$, which can be explained by the transformation of quartz at about $580{ }^{\circ} \mathrm{C}$ (see Figs. $8 \mathrm{~b}$ and 10). After $600{ }^{\circ} \mathrm{C}$, the CTE of FC and FCG reduced gradually. Overall, the CTE of sacrificial concrete was found to be in the range $1.0 \times 10^{-5}$ and $2.39 \times 10^{-5} 1 /{ }^{\circ} \mathrm{C}$, which is consistent with that of self-consolidating concrete subjected to elevated temperatures [51].

In addition, the CTE of FCG was always lower than that of $\mathrm{FC}$ above $700{ }^{\circ} \mathrm{C}$, which indicated that the addition of GSNSs to sacrificial concrete caused a reduction in its CTE. This is because the thermal gradient and thermal damage of sacrificial concrete can be reduced due to the high thermal conductivity of graphene and its derivatives, e.g., GSNSs [16]. Unlike the self-consolidating concrete as presented in [51], the CTE of sacrificial concrete did not decline suddenly, which suggested that the high temperature integrity of sacrificial concrete was higher than that of self-consolidating concrete. Moreover, the elevated temperature integrity of FCG was higher than that of FC after 700 ${ }^{\circ} \mathrm{C}$, which implied that the addition of GSNSs to sacrificial concrete could enhance its high temperature integrity.

\subsection{Density}

Based on the results of TGA and CTE, the mass loss ratio and volumetric CTE of sacrificial concrete can be obtained and are shown in Table 5. Fig.12 shows the density evolution of sacrificial concrete at elevated temperatures that was obtained using Eq. (7). The evolution of density for FC and FCG over temperature was similar, which is consistent with the weight evolution as shown in Fig.8a. There was a dramatic decrease in density when temperature changed from $25^{\circ} \mathrm{C}$ to $200{ }^{\circ} \mathrm{C}$, followed by a slightly less decrease in the range of $400-800{ }^{\circ} \mathrm{C}$ and a gradual drop in the range of $800-1000{ }^{\circ} \mathrm{C}$. Over the whole range of $25-1000{ }^{\circ} \mathrm{C}$, the density of FCG was higher than that of FC, which corresponded with the weight evolution as discussed above. In detail, the density of FCG at 
25,600 , and $1000{ }^{\circ} \mathrm{C}$ was, $0.26 \%, 0.54 \%$ and $0.87 \%$ respectively higher than that of $\mathrm{FC}$.

\subsection{Thermal diffusivity}

The thermal conductivity and the specific heat of sacrificial concrete without and with GSNSs at ambient and elevated temperatures were obtained simultaneously by mean of laser thermal constant analyzer, the results of which are presented in Table 6. Based on the obtained density of sacrificial concrete at ambient and each target temperature, the thermal diffusivity of sacrificial concrete could be calculated using Eq. (5), which is shown in Table 6 as well and is plotted in detail in Fig.13. The thermal diffusivity of sacrificial concrete decreased with increasing temperature reaching the minimum at $600{ }^{\circ} \mathrm{C}$ and then increased with the increase of temperature. In general, the thermal diffusivity of sacrificial concrete ranged from 0.29 to $1.36 \mathrm{~mm}^{2} / \mathrm{s}$ between ambient temperature and $1000^{\circ} \mathrm{C}$. In addition, the thermal diffusivity of FCG was always higher than that of FC in the range of $25-1000{ }^{\circ} \mathrm{C}$. It can be found that the thermal diffusivity of sacrificial concrete was increased by $25.00-103.23 \%$ due to the incorporation of GSNSs. For example, the thermal diffusivity of FCG at 25,600 and $1000{ }^{\circ} \mathrm{C}$ was $30.77 \%, 68.97 \%$ and $52.50 \%$ higher than that of $\mathrm{FC}$, respectively.

The higher thermal diffusivity of sacrificial concrete can help reduce its thermal gradient and thus diminish its thermal damage at high temperatures. These might explain why the residual compressive strength and splitting tensile strength of FCG were higher than that of FC over the whole range of 25$1000{ }^{\circ} \mathrm{C}$, as shown in Sections 3.3 and 3.4. As temperature increased, the thermal diffusivity of sacrificial concrete in the range of $25-600{ }^{\circ} \mathrm{C}$ decreased, which can be attributed to the evaporation of water, decomposition of hydrates and thermal cracks induced by high temperatures. These explanations have been already identified by previous studies $[30,49,52]$. When the temperature was higher than $600{ }^{\circ} \mathrm{C}$, the microstructure of sacrificial concrete was further deteriorated (see Fig. 2) and the porosity and damage were further increased, which resulted in the increase of thermal conductivity 
and specific heat, and the decrease of density. However, the increasing amplitude of thermal conductivity was higher than that of specific heat (see Table 6). Accordingly, the thermal diffusivity of sacrificial concrete tended to increase in the range of $600-1000{ }^{\circ} \mathrm{C}$.

It is worth noting that the aggregate type is the most important factor that affects the CTE of concrete [53]. Similar to the CTE of concrete, the thermal diffusivity of concrete may also be affected by the types and content of aggregates. However, the types and content of aggregates used in sacrificial concrete are basically fixed [29], thus the CTE and thermal diffusivity of sacrificial concrete obtained in the paper are reasonable.

\subsection{Ablation behaviour}

From the high temperature test through electrically furnace, the decomposition temperature of sacrificial concrete was found to be about $1120^{\circ} \mathrm{C}$. Fig. 14 shows the enthalpy of sacrificial concrete that was obtained from the DSC results presented in Fig. 8b. As temperature increased, the enthalpy of sacrificial concrete increased gradually followed by a sharp rise. The enthalpy of FCG was higher than that of $\mathrm{FC}$ in the range of $25-1200{ }^{\circ} \mathrm{C}$, while a contrary tendency can be observed after $1200{ }^{\circ} \mathrm{C}$, which is in accordance with the DSC results (see Fig. 8b). The decomposition enthalpy of FC and FCG was found to be $489.61 \mathrm{~kJ} / \mathrm{kg}$ and $510.32 \mathrm{~kJ} / \mathrm{kg}$, respectively. The latter was $4.23 \%$ higher that of the former. It can be seen from the definition of ablation velocity that the ablation velocity is directly proportional to heat flux, but inversely proportional to density, ablating area and decomposition enthalpy. Since the density and decomposition enthalpy of FCG were always higher than those of FC (see Figs. 12 and 14), the ablation velocity of FCG was lower than that of FC for the identical heat flux and ablating area. Compared to FC, the ablation velocity of FCG was reduced by $4.14 \%$ due to the incorporation of GSNSs, which implied that the melt-through time of basemat can be prolonged and thus the safety of nuclear power plant can be enhanced in severe nuclear 
accident by adding GSNSs to sacrificial concrete.

\section{Conclusions}

In this study, the mechanical and thermal properties of ferro-siliceous sacrificial concrete without and with GSNSs (i.e., FC and FCG) at high temperatures were investigated. Two new experimental facilities for measuring compressive strength and splitting tensile strength sacrificial concrete during elevated temperature exposure were developed and used. Based on the findings of this study, the following conclusions can be drawn:

- GSNSs had reinforcing and toughing effects on the microstructure of sacrificial concrete. The porosity of sacrificial concrete increased continually with increasing temperature. The porosity of sacrificial concrete was reduced by $3.01-6.99 \%$ due to the addition of GSNSs.

- The compressive strength and splitting tensile strength of sacrificial concrete decreased monotonically with the increase of temperature. For FCG, its compressive strength and splitting tensile strength were always higher than those of $\mathrm{FC}$ in the whole range of $25-1000^{\circ} \mathrm{C}$. Because of the incorporation of GSNSs, the compressive strength and splitting tensile strength of sacrificial concrete were increased by $12.98-25.36 \%$ and $8.66-34.38 \%$, respectively.

- The weight evolution of FC and FCG was similar, while weight loss of FCG is lower than that of FC in the range of $25-1300{ }^{\circ} \mathrm{C}$. The total weight loss of $\mathrm{FC}$ and $\mathrm{FCG}$ up to $1300^{\circ} \mathrm{C}$ was $7.64 \%$ and $6.62 \%$, respectively.

- The thermal strain of sacrificial concrete increased dramatically in the range of $25-600{ }^{\circ} \mathrm{C}$ followed by a gradual increase after $600{ }^{\circ} \mathrm{C}$. The thermal strain of FC and FCG was almost the same in the range of $25-700{ }^{\circ} \mathrm{C}$, while the thermal strain of FCG was lower than that of FC after $700{ }^{\circ} \mathrm{C}$ due to the addition of GSNSs.

- The coefficient of thermal expansion (CTE) of sacrificial concrete was found to be within the range 
of $1.0 \times 10^{-5}$ and $2.39 \times 10^{-5} 1 /{ }^{\circ} \mathrm{C}$. The elevated temperature integrity of FCG was higher than that of FC after $700{ }^{\circ} \mathrm{C}$, which suggested that the addition of GSNSs to sacrificial concrete can enhance its high temperature integrity.

- The thermal diffusivity of sacrificial concrete decreased as temperature increased from ambient temperature to $600{ }^{\circ} \mathrm{C}$ and then increased with increasing temperature. The thermal diffusivity of sacrificial concrete was increased by $25.00-103.23 \%$ due to the incorporation of GSNSs.

- The decomposition enthalpy of FCG was $4.23 \%$ higher that of FC and the ablation velocity of sacrificial concrete was reduced by $4.14 \%$ due to the incorporation of GSNSs, as such the safety of nuclear power plant can be improved by adding GSNSs to sacrificial concrete.

\section{Acknowledgements}

The research is finically supported by National Natural Science Foundation of China (No. 51378114, and 51611130205), Ministry of Science and Technology of China (973 program, 2015CB655105), and Transformation of Major Scientific, Technological Achievements of Jiangsu Province (No. 85120000220), and The Royal Society (IE150587), which are gratefully acknowledged. The authors also would like to thank Professor Haitang Zhu (Zhengzhou University) for his help with mechanical experiments.

\section{References}

[1] C. Nunes, Z. Slizkova, M. Stefanidou, J. Nemecek, Microstructure of lime and lime-pozzolana pastes with nanosilica, Cem. Concr. Res. 83 (2016) 152-163.

[2] M. Nili, A. Ehsani, Investigating the effect of the cement paste and transition zone on strength development of concrete containing nanosilica and silica fume, Mater. Des. 75 (2015) 174-183.

[3] P. Hou, K. Wang, J. Qian, S. Kawashima, D. Kong, S.P. Shah, Effects of colloidal nanoSiO 2 on fly ash hydration, Cem. Concr. Compos. 34 (2012) 1095-1103. 
[4] T. Menga, Y. Yub, X. Qiana, S. Zhana, K. Qiana, Effect of nano- $\mathrm{TiO}_{2}$ on the mechanical properties of cement mortar, Constr. Build. Mater. 29 (2012) 241-245.

[5] E. Mohseni, M.M. Khotbehsara, F. Naseri, M. Monazami, P. Sarker, Polypropylene fibre reinforced cement mortars containing rice husk ash and nano-alumina, Constr. Build. Mater. 111 (2016) 429-439.

[6] K. Behfarnia, N. Salemi, The effects of nano-silica and nano- alumina of frost resistance of normal concrete, Constr. Build. Mater. 48 (2013) 580-584.

[7] M.O.G.P. Braganca, K.F. Portella, M.M. Bonato, E. Alberti, C.E.B. Marino, Performance of Portland cement concretes with $1 \%$ nano- $\mathrm{Fe}_{3} \mathrm{O}_{4}$ addition: electrochemical stability under chloride and sulfate environments, Constr. Build. Mater. 117 (2016) 152-162.

[8] A.D’Alessandro, M. Rallini, F. Ubertini, A.L. Materazzi, J. M. Kenny, Investigation on scalable fabrication procedures for self-sensing carbon nanotube cement-matrix composites for SHM applications, Cem. Concr. Compos. 65 (2016) 200-213.

[9] S. Parveen, S. Rana, R. Fangueiro, M.C. Paiva, Microstructure and mechanical properties of carbon nanotube reinforced cementitious composites developed using a novel dispersion technique, Cem. Concr. Res. 73 (2015) 215-227.

[10] S.M.H. Farrash, M. Shariati, J. Rezaeepazhand, The effect of carbon nanotube dispersion on the dynamic characteristics of unidirectional hybrid composites: An experimental approach, Compos. Part B Eng. 122 (2017) 1-8.

[11] P. Hou, S. Kawashima, D. Kong, D.J. Corr, J. Qian, S.P. Shah, Modification effects of colloidal nanoSiO 2 on cement hydration and its gel property, Compos. Part B Eng. 45 (2013) 440-448.

[12] S. Lv, L. Deng, W. Yang, Q. Zhou, Y. Cui, Fabrication of polycarboxylate/graphene oxide nanosheet composites by copolymerization for reinforcing and toughening cement composites, 
Cem. Concr. Compos. 66 (2016) 1-9.

[13] D. Hou, Z. Lu, X. Li, H. Ma, Z. Li, Reactive molecular dynamics and experimental study of graphenecement composites: Structure, dynamics and reinforcement mechanisms, Carbon 115 (2017)188-208.

[14] K.S. Novoselov, A.K. Geim, S.V. Morozov, D. Jiang, M. Katsnelson, I. Grigorieva, A. Firsov, Two-dimensional gas of massless Dirac fermions in graphene, Nature 438 (7065) (2005) 197 200.

[15] V. Singh, D. Joung, L. Zhai, S. Das, S.I. Khondaker, S. Seal, Graphene based materials: past, present and future, Prog. Mater. Sci. 56 (8) (2011) 1178-1271.

[16] A.K. Geim, K.S. Novoselov, The rise of graphene, Nat. Mater. 6 (2007) 183-191.

[17] W. Lv, Z. Li, Y. Deng, Q. Yang, F. Kang, Graphene-based materials for electrochemical energy storage devices: Opportunities and challenges, Energy Storage Mater. 2 (2016) 107-138.

[18] Z. Pan, L. He, L. Qiu, A.H. Korayem, G. Li, J.W. Zhu, F. Collins, D. Li, W.H. Duan, M.C. Wang, Mechanical properties and microstructure of a graphene oxide-cement composite, Cem. Concr. Compos. 58 (2015) 140-147.

[19] V. Chabot, D. Higgins, A. Yu, X. Xiao, Z. Chen, J. Zhang, A review of graphene and graphene oxide sponge: material synthesis and applications to energy and the environment, Energy Environ. Sci. 7 (5) (2014) 1564-1596.

[20] J.L. Le, H. Du, S.D. Pang, Use of 2D graphene nanoplatelets (GNP) in cement composites for structural health evaluation, Compos. Part B Eng. 67 (2014) 555-563.

[21] Y. Zhu, S. Murali, W. Cai, X. Li, J.W. Suk, J.R. Potts, R.S. Ruoff, Graphene and graphene oxide: synthesis, properties, and applications, Adv. Mater. 22 (35) (2010) 3906-3924.

[22] J. Kim, L.J. Cote, F. Kim, W. Yuan, K.R. Shull, J. Huang, Graphene oxide sheets at inerfaces, J. 
Am. Chem. Soc. 132 (23) (2010) 8180-8186.

[23] E. Horszczaryk, E. Mijowska, R.J. Kalenczuk, M. Aleksandrzak, S. Mijowska, Nanocomposite of cement/graphene oxide - impact on hydration kinetics and Young's modulus, Constr. Build. Mater. 78 (2015) 234-242.

[24] M. Bulut, Mechanical characterization of Basalt/epoxy composite laminates containing graphene nanopellets, Compos. Part B Eng. 122 (2017) 71-78.

[25] M. Murugan, M. Santhanam, S.S. Gupta, T. Pradeep, S.P. Shah, Influence of 2D rGO nanosheets on the properties of OPC paste, Cem. Concr. Compos. 70 (2016) 48-59.

[26] Z. Lu, D. Hou, L. Meng, G. Sun, C. Lu, Z. Li, Mechanism of cement paste reinforced by graphene oxide/carbon nanotubes composites with enhanced mechanical properties, RSC Adv. 5 (2015) 100598-100605.

[27] H. Chu, J. Chen, The experimental study on the correlation of resistivity and damage for conductive concrete, Cem. Concr. Compos. 67 (2016) 12-19.

[28] H. Chu, J. Jiang, W. Sun, M. Zhang, Thermal behaviour of siliceous and ferro-siliceous sacrificial concrete subjected to elevated temperatures, Mater. Des. 95 (2016) 470-480.

[29] R.J.M. Konings, T.R. Allen, R.E. Stoller, S. Yamanaka, Comprehensive nuclear materials. Amsterdam: Elsevier. 2012.

[30] S.C. Kou, C.S. Poon, M. Etxeberria, Residue strength, water absorption and pore size distributions of recycled aggregate concrete after exposure to elevated temperatures, Cem. Concr. Compos. 53 (2014) 73-82.

[31] H. Fares, A. Noumowe, S. Remond, Self-consolidating concrete subjected to high temperature mechanical and physicochemical properties, Cem. Concr. Res. 39 (2009) 1230-1238.

[32] F.L. Monte, P.G. Gambarova, Thermo-mechanical behaviour of baritic concrete exposed to high 
temperature, Cem. Concr. Compos. 53 (2014) 305-315.

[33] A. Behnood, H. Ziari, Effects of silica fume addition and water to cement ratio on the properties of high-strength concrete after exposure to high temperatures, Cem. Concr. Compos. 30 (2008) 106-112.

[34] Z. Pan, J.G. Sanjayan, F. Collins, Effect of transient creep on compressive strength of geopolymer concrete for elevated temperature exposure, Cem. Concr. Res. 56 (2014) 182-189.

[35] H. Chu, J. Jiang, W. Sun, M. Zhang, Mechanical and physicochemical properties of ferrosiliceous concrete subjected to elevated temperatures, Constr. Build. Mater. 122 (2016) 743-752.

[36] H.-y. Chu, J.-y. Jiang, W. Sun, M. Zhang, Effect of graphene sulfonate nanosheets on mechanical and thermal properties of sacrificial concrete during high temperature exposure, Cem. Concr. Compos. 82 (2017) 252-264.

[37] M.W. Chase, NIST-JANAF Thermochemical Tables, Journal of Physical and Chemical Reference Data, Monograph 9, fourth ed., Springer, Berlin, 1998.

[38] L.T. Phan, N.J. Carino, Effects of test conditions and mixture proportions on behaviour of highstrength concrete exposed to high temperatures, ACI Mater. J. 99 (1) (2002) 54-66.

[39] F.J. Ulm, O. Coussy, Z.P. Bazant, The chunnel fire: chemoplastic softening in rapidly heated concrete, J. Eng. Mech. 125(3) (1999) 272-282.

[40] T. Ramanathan, A.A. Abdala, S. Stankovich, D.A. Dikin, A.M. Herrera, R.D. Piner, Functionalized graphene sheets for polymer nanocomposites, Nat. Nano. 3(6) (2008) 327-331.

[41] M.J. Heap, Y. Lavallee, A. Laumann, K.U. Hess, P.G. Meredith, D.B. Dingwell, S. Huismann, F. Weise, The influence of thermal-stressing (up to $1000{ }^{\circ} \mathrm{C}$ ) on the physical, mechanical, and chemical properties of siliceous-aggregate, high-strength concrete, Constr. Build. Mater. 42 (2013) 248-265. 
[42] P. Pliya, A.L. Beaucour, A. Noumowe, Contribution of cocktail of polypropylene and steel fibres in improving the behaviour of high strength concrete subjected to high temperature, Constr. Build. Mater. 25 (2011) 1926-1934.

[43] C. Galle, J. Sercombe, Permeability and pore structure evolution of silicocalcareous and hematite high-strength concretes submitted to high temperatures, Mater. Struct. 34 (2001) 619-628.

[44] H.T. Le, M. Muller, K. Siewert, H.M. Ludwig, The mix design for self-compacting high performance concrete containing various mineral admixtures, Mater. Des. 72 (2015) 51-62.

[45] A.S. El-Dieb, Mechanical, durability and microstructural characteristics of ultra-high-strength self-compacting concrete incorporating steel fibres, Mater. Des. 30 (2009) 4286-4292.

[46] D. Hou, D. LI, T. Zhao, Z. Li, Confined water dissociation in disordered silicate nanometerchannels at elevated temperatures: mechanism, dynamics and impact on substrates, Langmuir, 32 (2016) 4153-4168.

[47] A. Behnood, M. Ghandehari, Comparison of compressive and splitting tensile strength of highstrength concrete with and without polypropylene fibres heated to high temperatures, Fire Saf. J. 44 (2009) 1015-1022.

[48] G. Ye, X. Liu, D.G. Schutter, Phase distribution and microstructural changes of self-compacting cement paste at elevated temperature, Cem. Concr. Res. 37(6) (2007) 978-987.

[49] Z.P. Bazant, M.F. Kaplan, Concrete at High Temperatures: Materials Properties and Mathematical Models, Longman, London, 1996.

[50] L. Zuda, R. Cerny, Measurement of linear thermal expansion coefficient of alkali-activated aluminaosilicate composites up to $1000^{\circ} \mathrm{C}$, Cem. Concr. Compos. 31(4) (2009) 263-267.

[51] T. Uygunoglu, I.B. Topcu, Thermal expansion of self-consolidating normal and lightweight aggregate concrete at elevated temperature, Constr. Build. Mater. 23 (2009) 3063-3069. 
[52] Z. Xing, A.L. Beaucour, R. hebert, A. Noumowe, B. Ledesert, Influence of the nature of aggregates on the behaviour of concrete subjected elevated temperature, Cem. Concr. Res. 41 (2011) 392-402.

[53] C. Zhou, X. Shu, B. Huang, Predicting concrete coefficient of thermal expansion with an improved micromechanical model, Constr. Build. Mater. 68 (2014) 10-16. 
Table 1 Chemical composition of cement and supplementary cementitious materials (wt\%)

\begin{tabular}{llll}
\hline Materials & Cement & Silica fume & Fly ash \\
\hline $\mathrm{CaO}$ & 64.70 & 0.77 & 8.38 \\
$\mathrm{SiO}_{2}$ & 20.40 & 96.18 & 47.96 \\
$\mathrm{Al}_{2} \mathrm{O}_{3}$ & 4.70 & 0.96 & 30.46 \\
$\mathrm{Fe}_{2} \mathrm{O}_{3}$ & 3.38 & 0.85 & 5.91 \\
$\mathrm{MgO}$ & 0.87 & 0.74 & 2.60 \\
$\mathrm{SO}_{3}$ & 1.88 & 0.50 & 1.32 \\
$\mathrm{~K}_{2} \mathrm{O}$ & 0.83 & & 1.61 \\
$\mathrm{Na}_{2} \mathrm{O}$ & & & 1.76 \\
$\mathrm{Loss}$ & 3.24 & & \\
\hline
\end{tabular}

Table 2 Particle size distribution of the aggregates (wt $\%$ )

\begin{tabular}{lllllll}
\hline Particle size $(\mathrm{mm})$ & $0-0.15$ & $0.15-0.30$ & $0.30-0.63$ & $0.63-2.36$ & $2.36-4.75$ & $4.75-8.00$ \\
\hline Silica sand & 6.30 & 7.60 & 13.50 & 14.60 & 11.50 & 46.50 \\
Iron ore & 5.20 & 7.10 & 12.70 & 39.00 & 17.80 & 18.20 \\
\hline
\end{tabular}


Table 3 Physical and mechanical properties of polypropylene fibre

\begin{tabular}{ll}
\hline Technical specification & Polypropylene fibre \\
\hline Purity $(\%)$ & 100 \\
Length $(\mathrm{mm})$ & 12 \\
Diameter $(\mu \mathrm{m})$ & 18 \\
Density $\left(\mathrm{kg} / \mathrm{m}^{3}\right)$ & 910 \\
Melting temperature $\left({ }^{\circ} \mathrm{C}\right)$ & 169 \\
Burning temperature $\left({ }^{\circ} \mathrm{C}\right)$ & 590 \\
Young's modulus $(\mathrm{MPa})$ & $>3500$ \\
Tensile strength $(\mathrm{MPa})$ & 386 \\
\hline
\end{tabular}


Table 4 Mix proportions of sacrificial concrete $\left(\mathrm{kg} / \mathrm{m}^{3}\right)$

\begin{tabular}{lcc}
\hline Mixture & FC & FCG \\
\hline Cement & 388 & 388 \\
Fly ash & 135 & 135 \\
Silica fume & 20.0 & 20.0 \\
Iron ore (0-4 mm) & 764 & 764 \\
Iron ore (4-8 mm) & 216 & 216 \\
Silica sand (0-5 mm) & 594 & 594 \\
Silica sand (5-8 mm) & 466 & 466 \\
Water & 181 & 181 \\
Superplasticizer & 8.00 & 8.00 \\
Polypropylene fibres & 1.40 & 1.40 \\
GSNSs & 0.543 \\
\hline
\end{tabular}


Table 5 Mass loss ratio and volumetric coefficient of thermal expansion of sacrificial concrete

\begin{tabular}{|c|c|c|c|c|}
\hline \multirow{2}{*}{$\begin{array}{c}\text { Temperature } \\
\left({ }^{\circ} \mathrm{C}\right)\end{array}$} & \multicolumn{2}{|c|}{ Mass loss ratio $(\gamma) \times 10^{-2}$} & \multicolumn{2}{|c|}{ Volumetric CTE $(\beta) \times 10^{-5}$} \\
\hline & $\mathrm{FC}$ & $\mathrm{FCG}$ & $\mathrm{FC}$ & $\mathrm{FCG}$ \\
\hline 25 & 0 & 0 & 0 & 0 \\
\hline 200 & 2.38 & 2.12 & 3.40 & 3.12 \\
\hline 400 & 3.43 & 3.08 & 4.75 & 4.64 \\
\hline 600 & 4.32 & 4.04 & 7.31 & 7.15 \\
\hline 800 & 6.03 & 5.42 & 5.57 & 5.34 \\
\hline 1000 & 6.18 & 5.61 & 4.52 & 4.28 \\
\hline
\end{tabular}

Table 6 Thermal properties of sacrificial concrete before and during exposure to elevated temperatures

\begin{tabular}{|c|c|c|c|c|c|c|}
\hline \multirow{2}{*}{$\begin{array}{l}\text { Temperature } \\
\left({ }^{\circ} \mathrm{C}\right)\end{array}$} & \multicolumn{2}{|c|}{$\begin{array}{l}\text { Thermal conductivity } \\
\qquad[\mathrm{W} /(\mathrm{m} \cdot \mathrm{K})]\end{array}$} & \multicolumn{2}{|c|}{$\begin{array}{l}\text { Specific heat } \\
{[\mathrm{J} /(\mathrm{g} \cdot \mathrm{K})]}\end{array}$} & \multicolumn{2}{|c|}{$\begin{array}{c}\text { Thermal diffusivity } \\
\left(\mathrm{mm}^{2} / \mathrm{s}\right)\end{array}$} \\
\hline & $\mathrm{FC}$ & FCG & $\mathrm{FC}$ & FCG & $\mathrm{FC}$ & $\mathrm{FCG}$ \\
\hline 25 & 2.09 & 2.56 & 0.75 & 0.70 & 1.04 & 1.36 \\
\hline 200 & 1.44 & 1.68 & 0.86 & 0.80 & 0.64 & 0.80 \\
\hline 400 & 1.06 & 1.56 & 0.95 & 0.82 & 0.43 & 0.73 \\
\hline 600 & 0.93 & 1.27 & 1.23 & 1.00 & 0.29 & 0.49 \\
\hline 800 & 1.05 & 2.07 & 1.45 & 1.08 & 0.31 & 0.63 \\
\hline 1000 & 1.45 & 2.82 & 1.62 & 1.35 & 0.40 & 0.61 \\
\hline
\end{tabular}



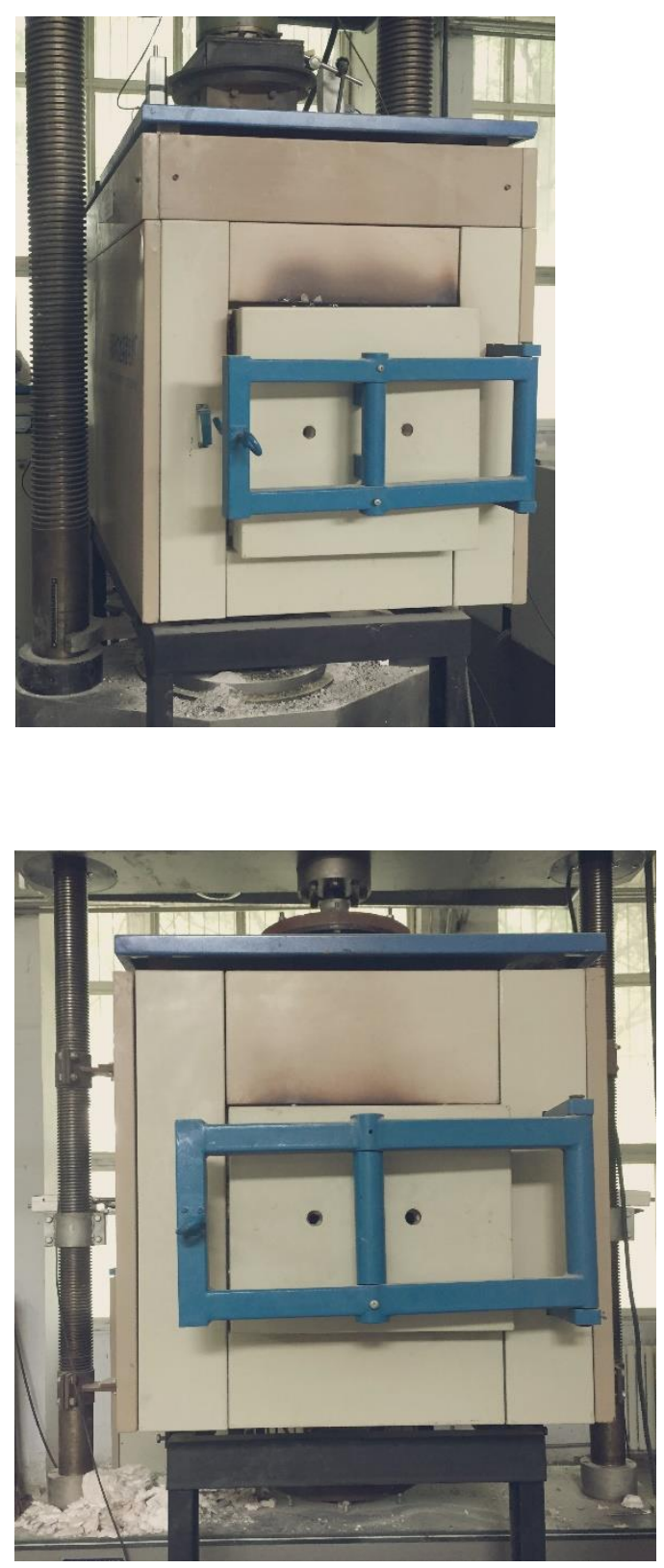

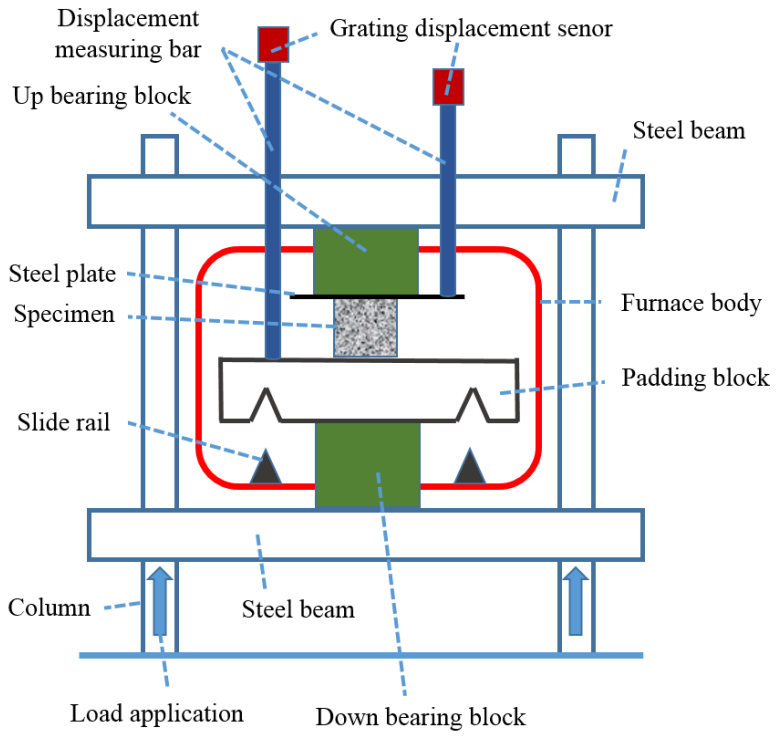

(a)

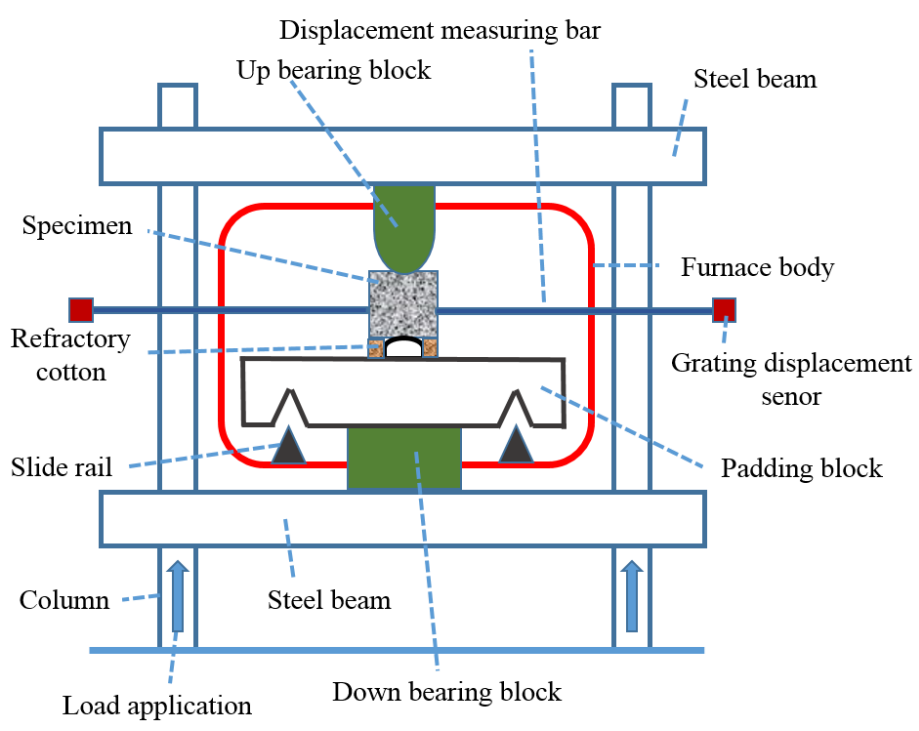

(b)

Fig. 1 New testing setups for measuring mechanical properties during exposure to high temperatures: (a) compressive strength; (b) splitting tensile strength 

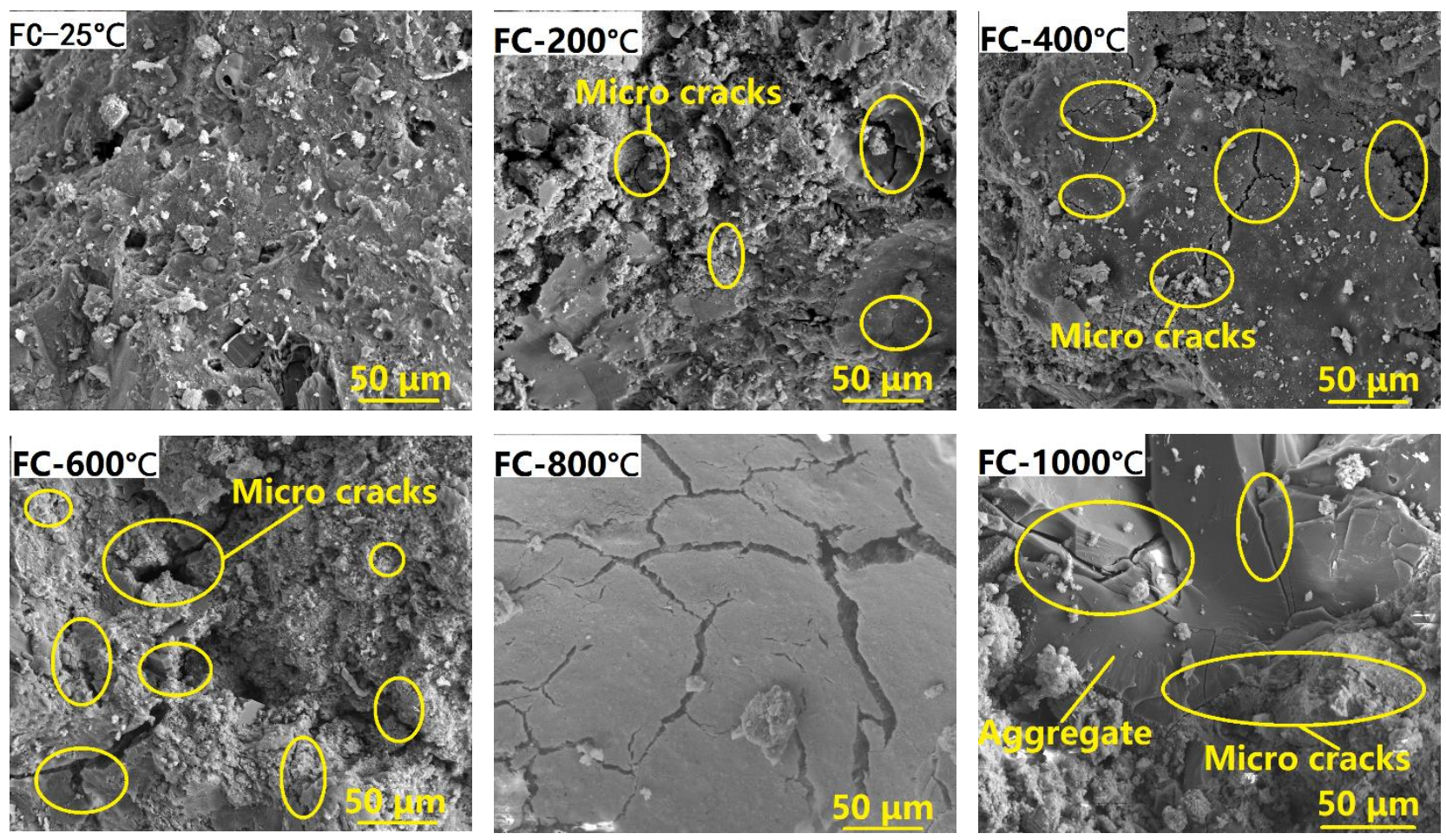

(a)
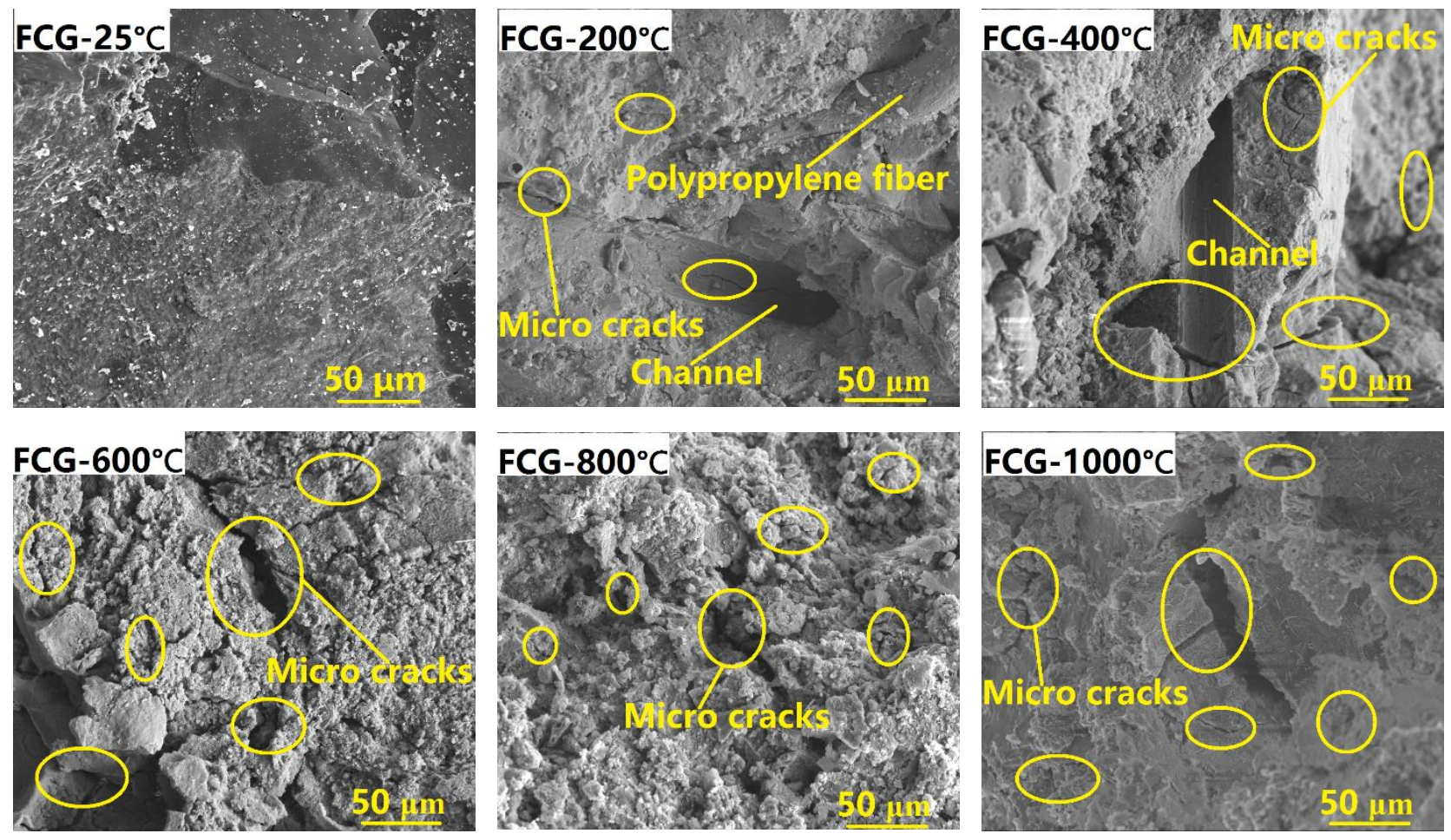

(b)

Fig. 2 ESEM images of specimens before and after exposure to different temperatures: (a) sacrificial concrete without GSNSs (FC); (b) sacrificial concrete with GSNSs (FCG) 


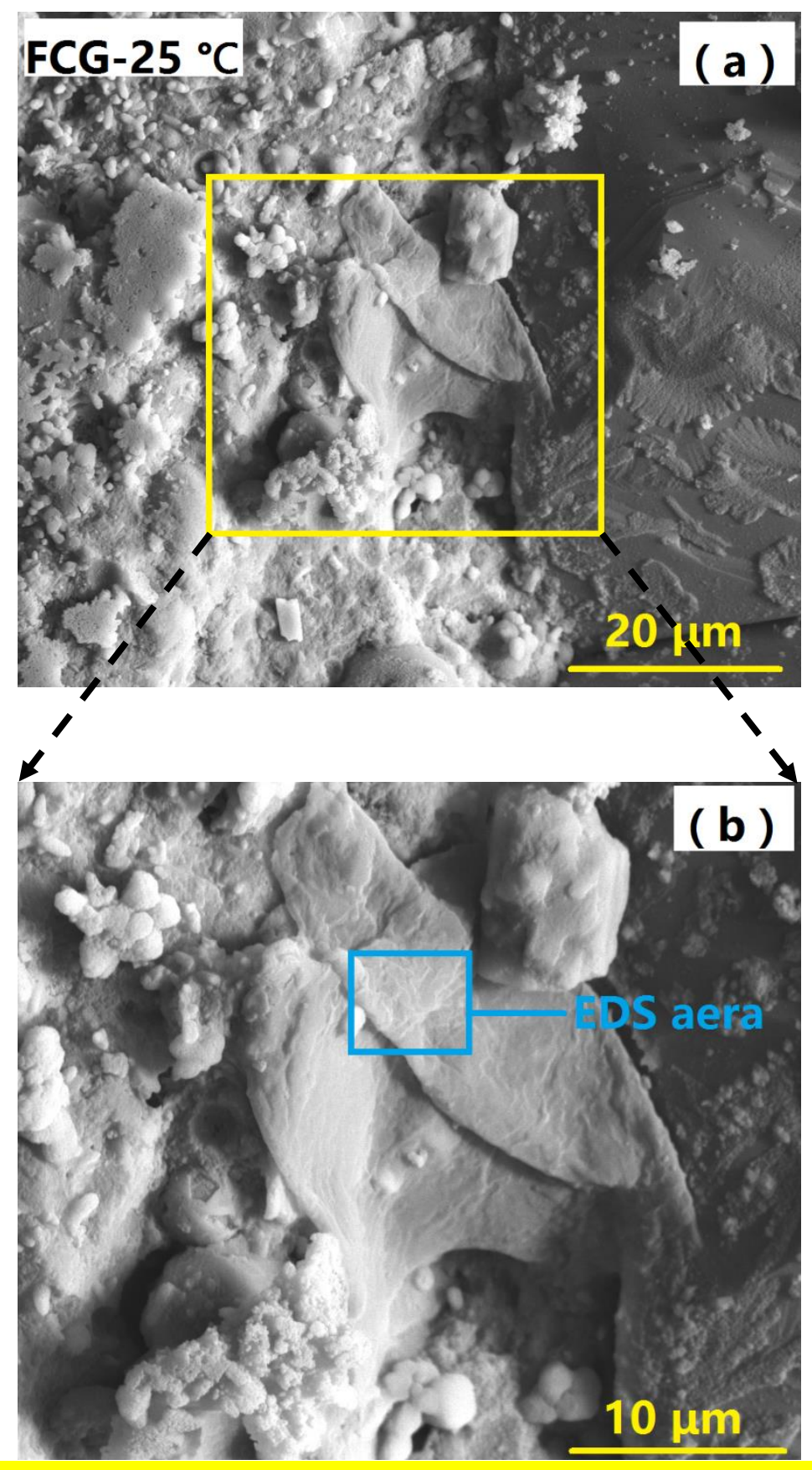

Fig. 3 Microstructure of sacrificial concrete with cumulative plate-shaped products 


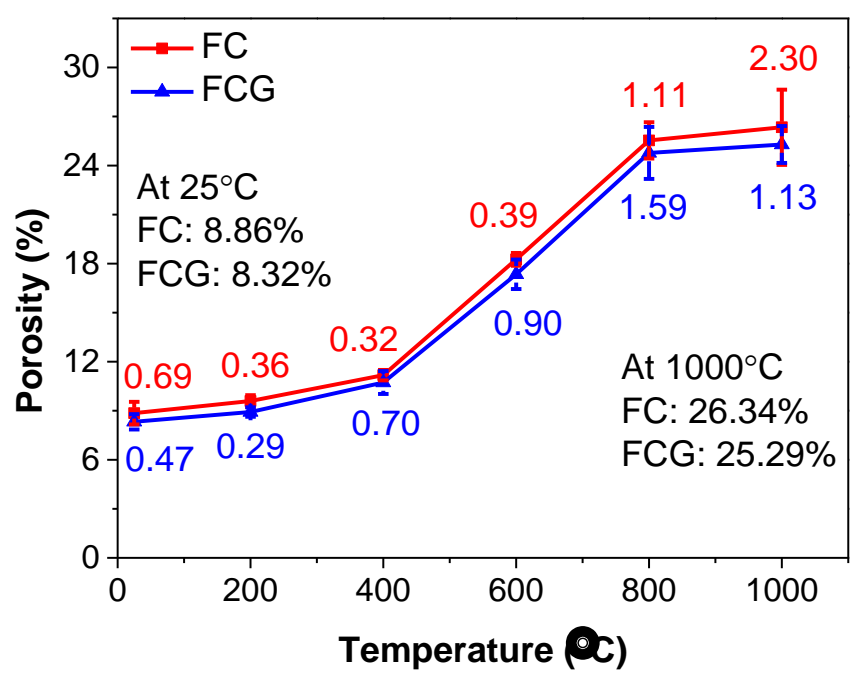

(a)

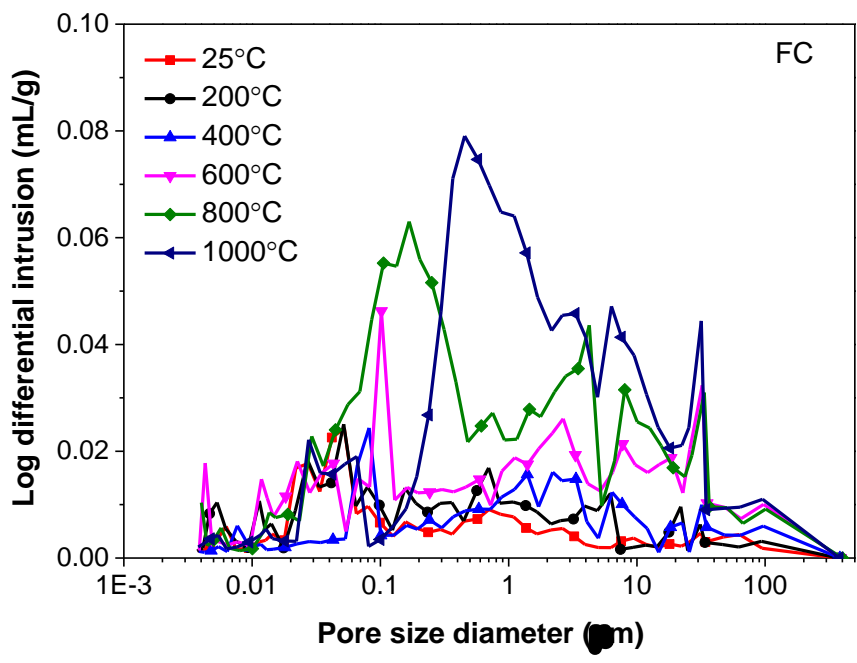

(b)

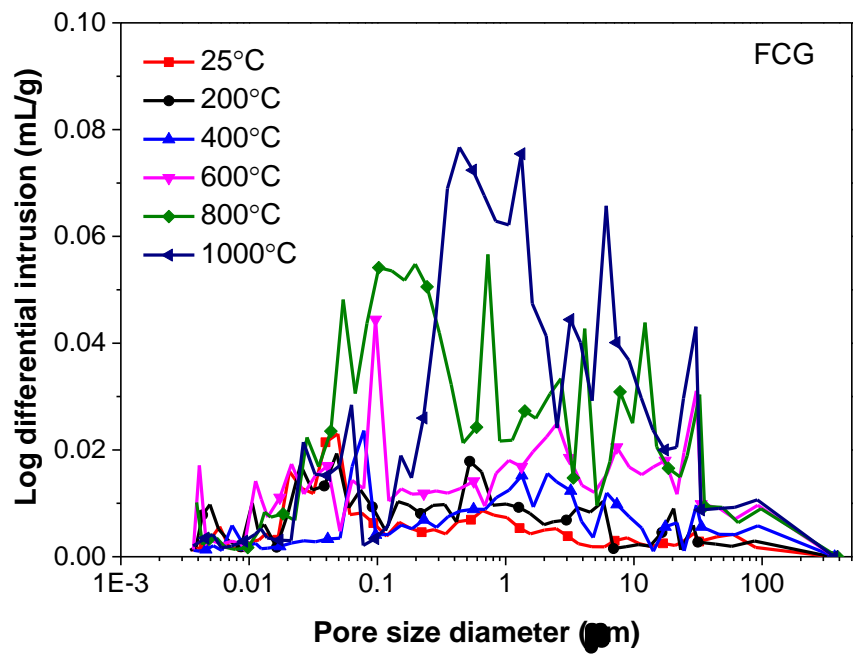

(c)

Fig. 4 Porosity and pore size distribution of sacrificial concrete after exposure to elevated temperatures: (a) porosity; (b) pore size distribution of FC; and (c) pore size distribution of FCG 


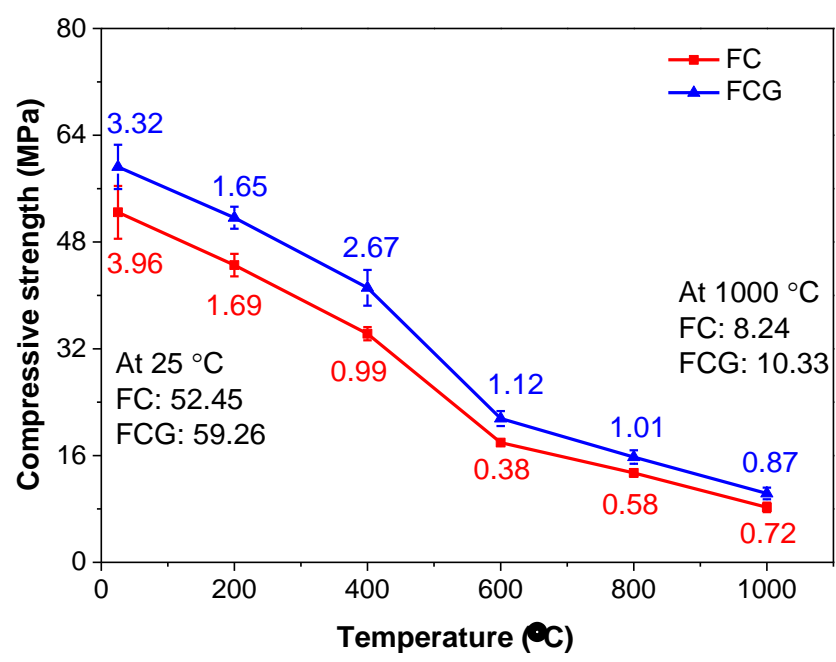

(a)

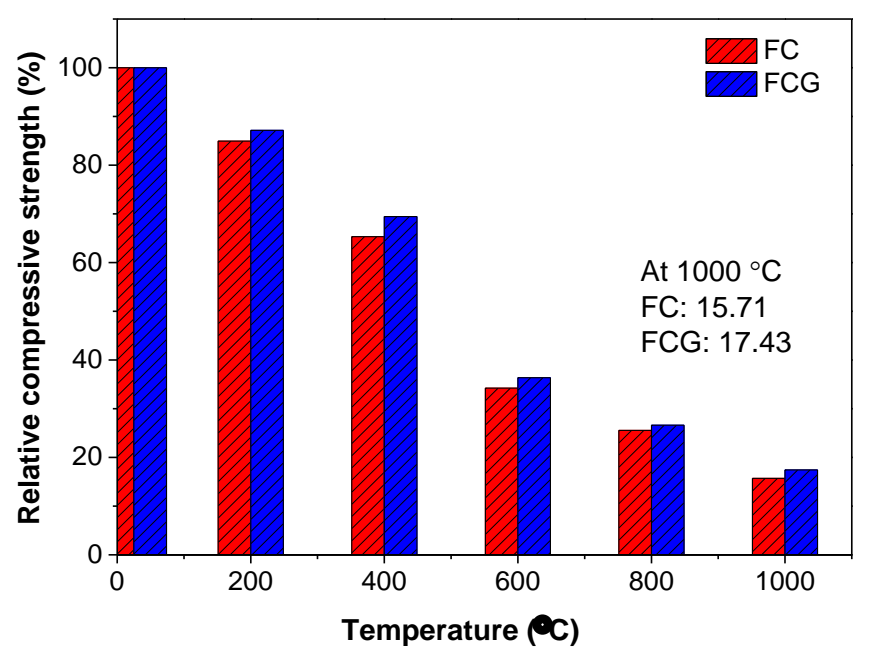

(b)

Fig. 5 Compressive strength of sacrificial concrete after exposure to elevated temperatures: (a) residual compressive strength; and (b) relative residual compressive strength (compared to strength at $25^{\circ} \mathrm{C}$ ) 


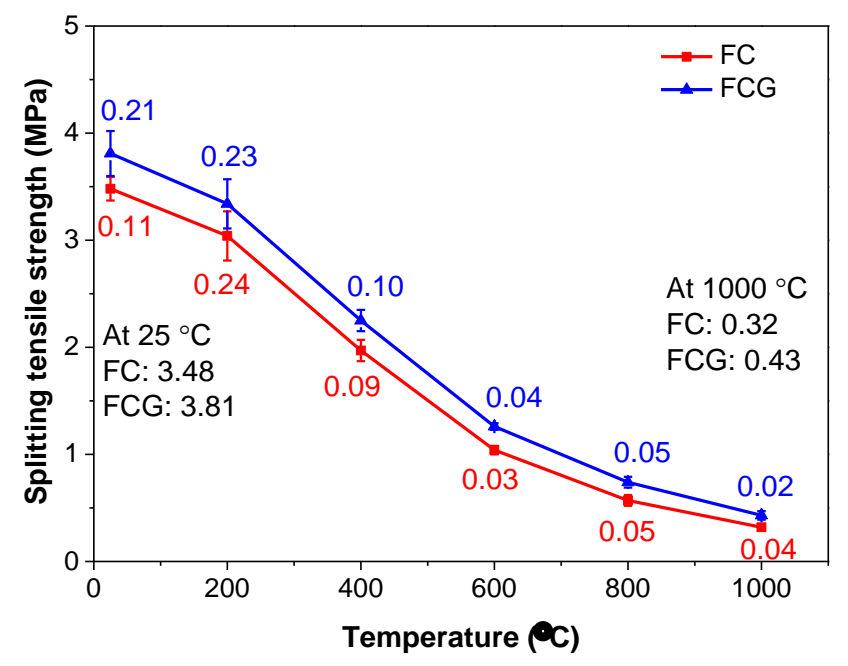

(a)

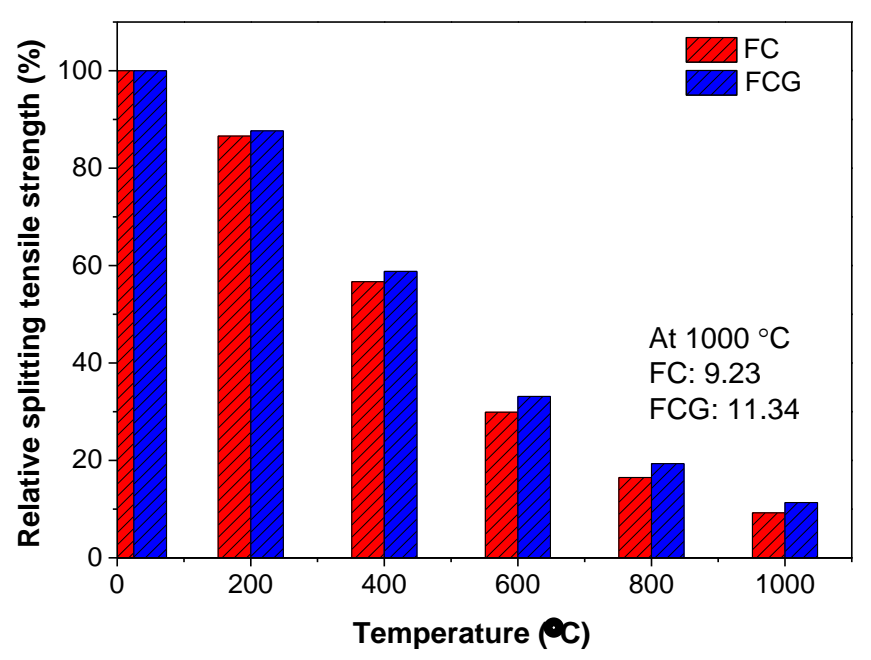

(b)

Fig. 6 Splitting tensile strength of sacrificial concrete after exposure to elevated temperatures: (a) residual splitting tensile strength; and (b) relative residual splitting tensile strength (compared to strength at $25^{\circ} \mathrm{C}$ ) 


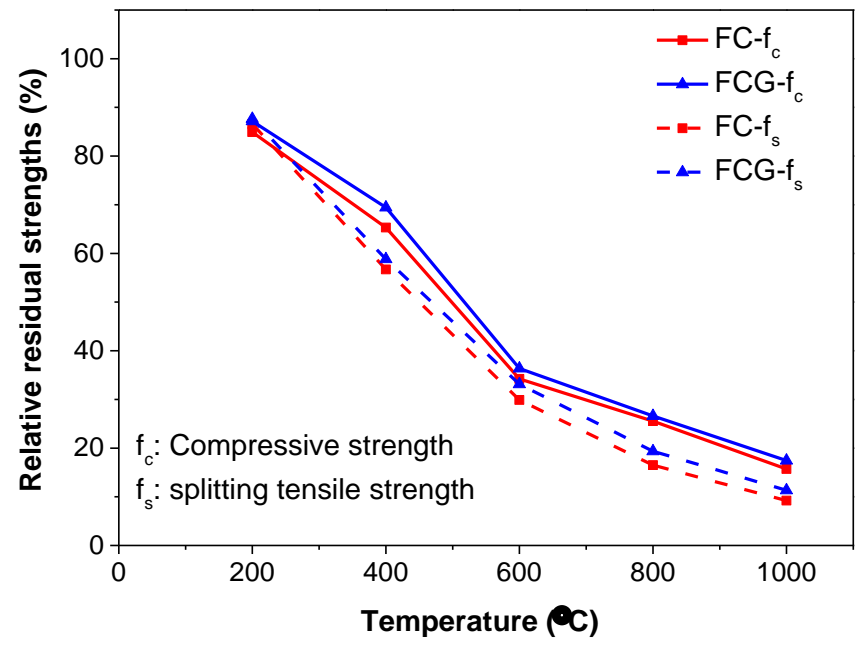

Fig. 7 Relative strength of sacrificial concrete after exposure to elevated temperatures 


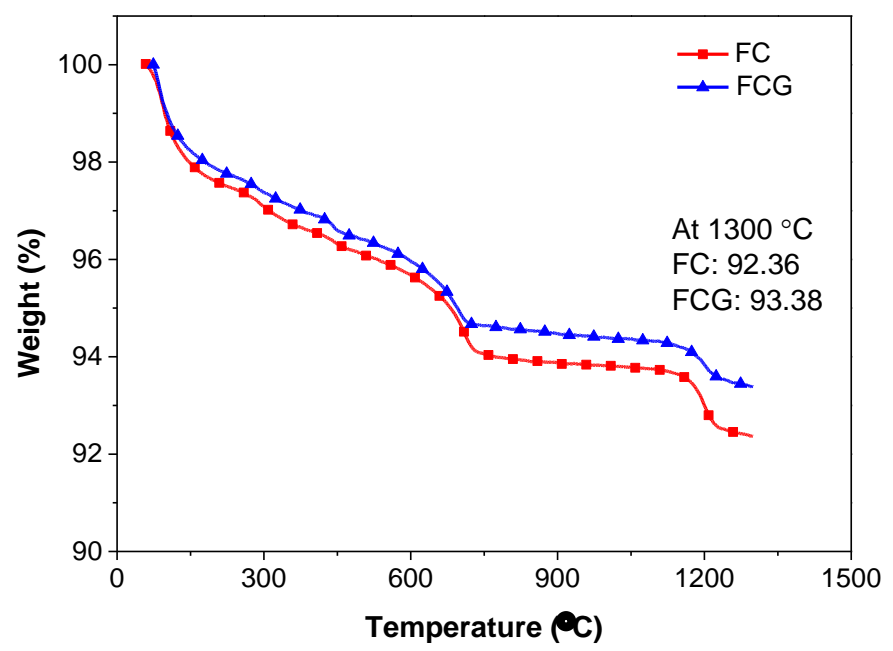

(a)

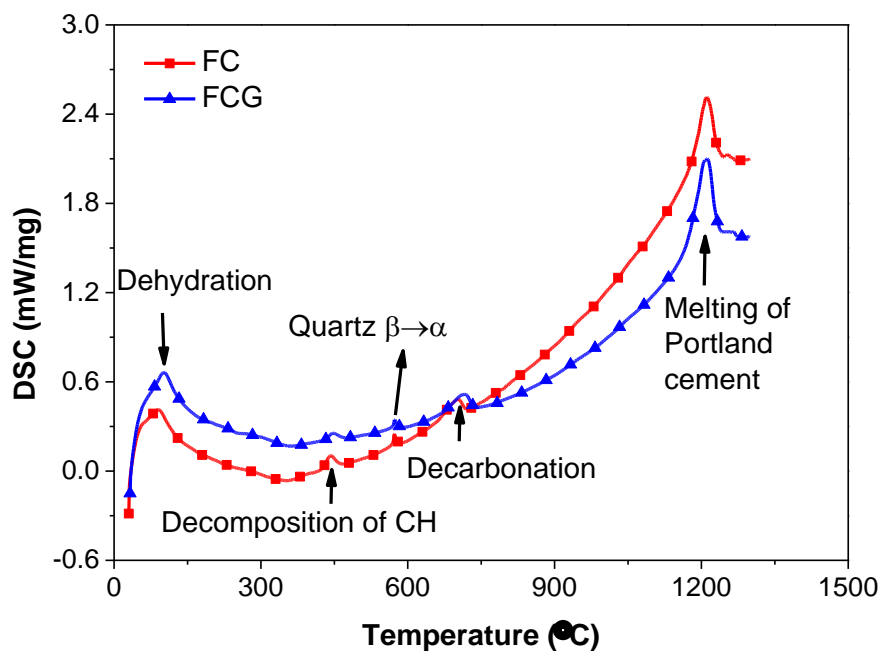

(b)

Fig. 8 Thermal analysis of sacrificial concrete: (a) TGA curves; and (b) DSC spectrums 


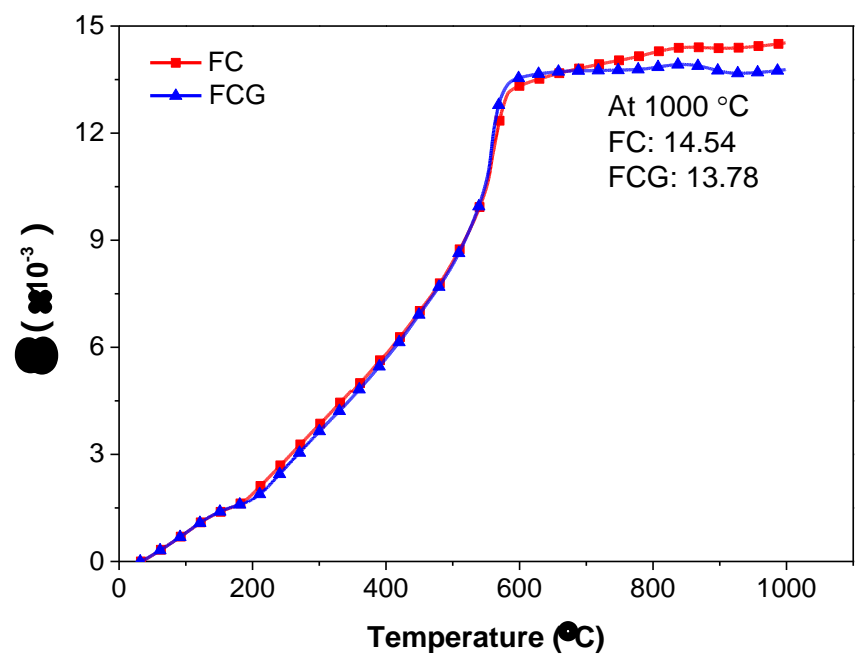

Fig. 9 Thermal strain of sacrificial concrete without and with GSNSs 


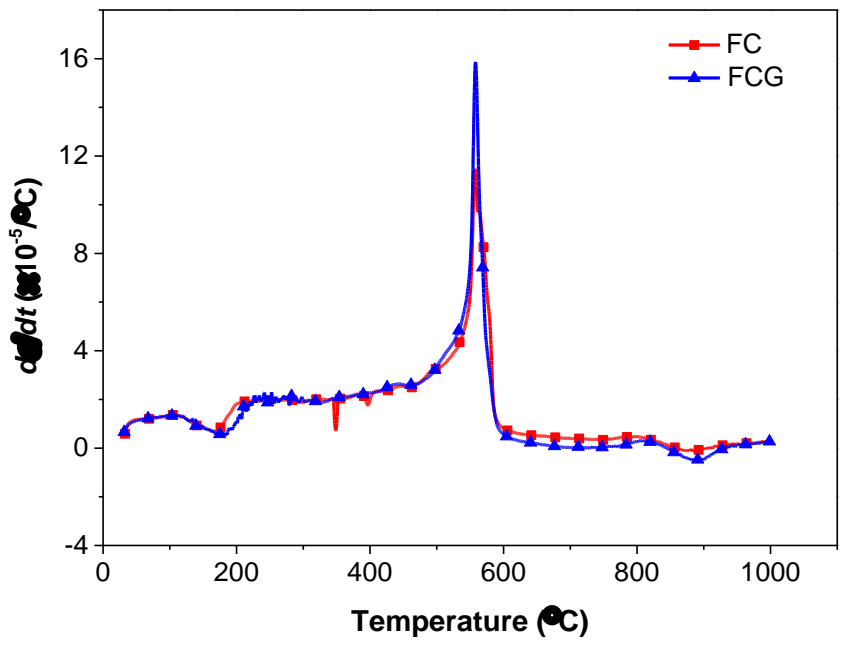

Fig. 10 First derivation of thermal strain of sacrificial concrete without and with GSNSs 


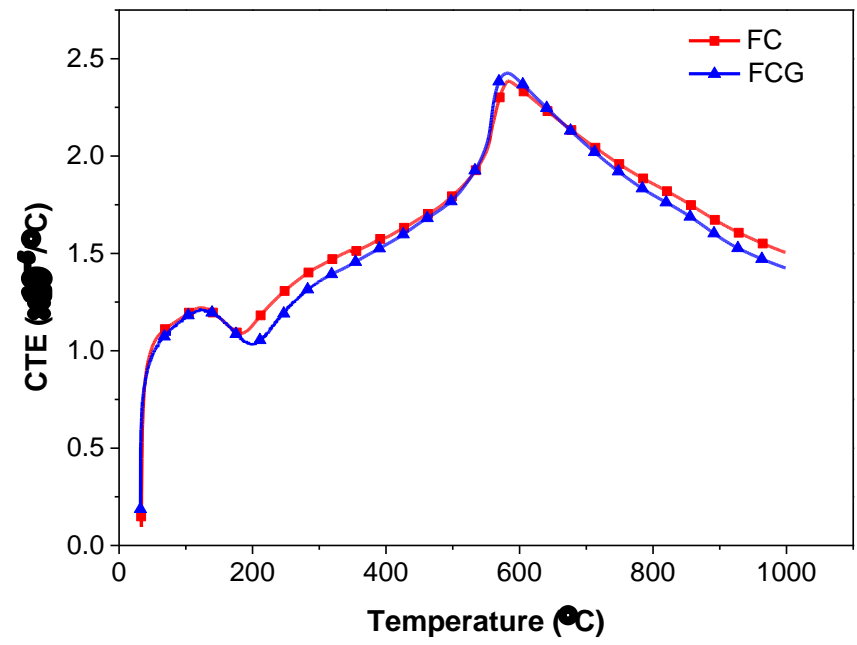

Fig. 11 Coefficient of thermal expansion of sacrificial concrete without and with GSNSs 


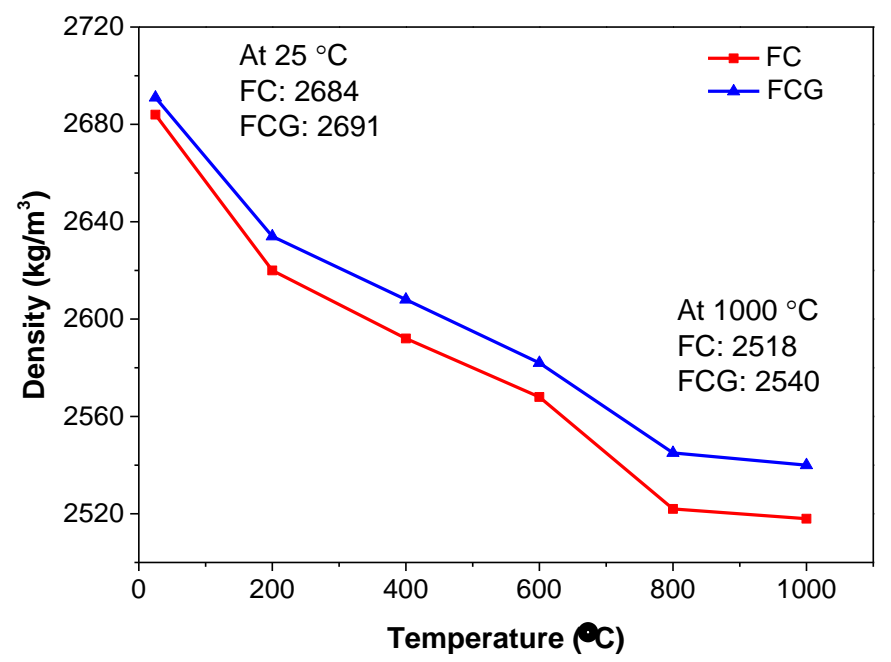

Fig. 12 Density evolution of sacrificial concrete without and with GSNSs 


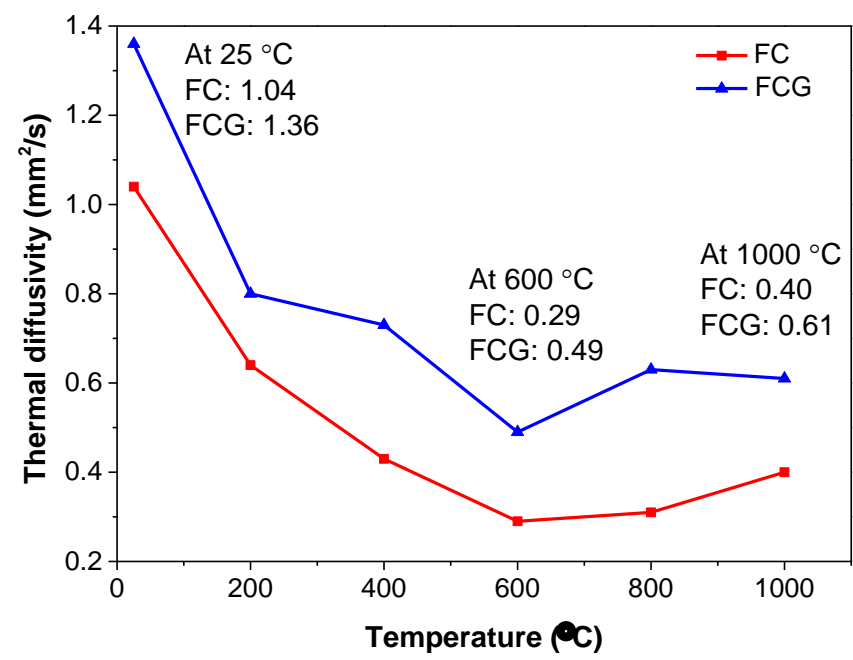

Fig. 13 Thermal diffusivity of sacrificial concrete without and with GSNSs 


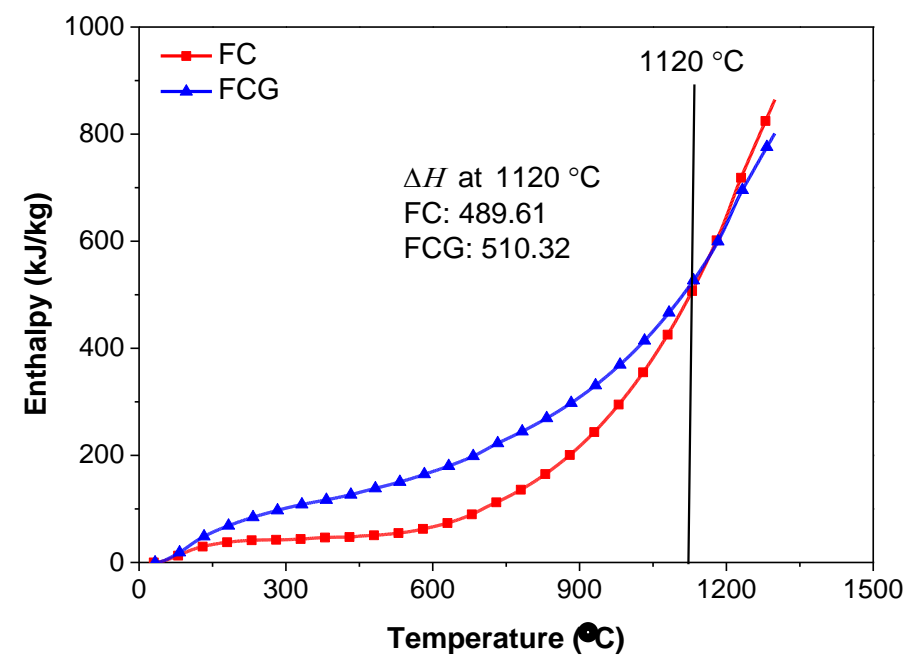

Fig. 14 Enthalpy and decomposition enthalpy (at $1120^{\circ} \mathrm{C}$ ) of sacrificial concrete without and with GSNSs 